\title{
A direct approach to modelling the complex response of magnesium AZ31 alloy sheets to variable strain amplitude loading using Prandtl-Ishlinskii operators
}

\author{
Urša Šolinc $^{\mathrm{a}}$, Jernej Klemenc ${ }^{\mathrm{a}}$, Marko Nagode ${ }^{\mathrm{a}}$, Domen Šeruga ${ }^{\mathrm{a}, *}$ \\ ${ }^{a}$ University of Ljubljana, Faculty of Mechanical Engineering, Aškerčeva 6, SI-1000 Ljubljana, Slovenia
}

\begin{abstract}
A new approach to modelling the complex behaviour of magnesium AZ31 alloy subjected to arbitrary uniaxial cyclic loading is introduced. Based on the Prandtl-Ishlinskii rheological model, one side play operators are applied so as to simulate the ascending and descending parts of asymmetric hysteresis loops separately. From the known material response to constant amplitude uniaxial loading, the Prandtl-Ishlinskii rheological model gives a fast and accurate simulation of the magnesium AZ31 alloy sheets response to arbitrary uniaxial loading under isothermal conditions. The approach represents a valuable starting point for estimating fatigue life using the energy approach for magnesium alloys.
\end{abstract}

Keywords: uniaxial cyclic loading, variable amplitude loading, magnesium alloy, AZ31 Mg, material model, rheological model, one side play operator, Prandtl-Ishlinskii operator

\section{Introduction}

Magnesium alloys are characterised by low density $\left(1.74 \mathrm{~g} / \mathrm{cm}^{3}\right)$, relatively high specific strength and rigidity compared to steel and aluminium alloys. In recent years, the excellent strength-to-weight ratio of magnesium alloys has proved to be attractive most notably to the transport industry, which is challenged by rising demands for a reduction in fuel consumption [1-3]. The mechanical properties of magnesium alloys are different from

\footnotetext{
*Corresponding author

Email address: domen.seruga@fs.uni-1j.si (Domen Šeruga)
} 
that of steel or aluminium alloys due to their hexagonal crystal structure which causes low ductility at room temperatures as well as significant asymmetry in yielding and hardening [4] 8 . Tensile yield stress can be as much as twice the value of the compressive yield stress [9, 10]. Extensive studies of the material behaviour have shown that twinning is the dominant plastic deformation mechanism for magnesium alloys under uniaxial compression at room temperature [9, 11 14]. The compressive hardening curve is characterised by low yield stress followed by an inflected hardening curve, with an increasing hardening rate for larger strains [11, 15-18]. In contrast, the dominant plastic deformation mechanism under uniaxial tension is crystallographic slip with a concave hardening curve typical for steels or aluminium alloys [11, 15 18]. In some applications, components must be designed to operate under repeated reverse loading, therefore cyclic loading behaviour needs to be understood in addition to monotonic loading behaviour. Previous studies of the plastic deformation behaviour of magnesium alloys under reverse loading or unloading have revealed that a twinned material can undergo untwinning. Untwinning is characterised by the disappearance of existing twins, which results in an inflected S-shaped hardening curve [9, 11, 12, 19 21]. Twins can reappear under reloading [22]. Although extensive research has been carried out on the cyclic plastic deformation behaviour of magnesium alloys under constant loading amplitudes [11, 23 31, little is known of the behaviour under variable cyclic loading. A reliable material model for magnesium alloys, validated for arbitrary cyclic loading, enables development of energy based damage models for evaluation of fatigue behaviour and prediction of fatigue life [32, 33].

This study focuses on developing an efficient rheological model for simulating the response of magnesium AZ31 alloy under uniaxial variable strain amplitude loading at room temperature. The cyclic uniaxial response is usually defined using cyclic material properties together with the Masing model [34] for constant amplitude loading or with the Madelung's memory rules extension of the Masing model [35, 36] for variable amplitude loading. For Masing materials, the cyclic curve represents the actual shape of a hysteresis loop which is symmetric in both the ascending and descending parts. Due to asymmetric material 
properties of magnesium AZ31 alloy, an appropriate model should be chosen that supports the asymmetric behaviour of non Masing materials. Hitherto, two main approaches have been used to describe the complex deformational behaviour of magnesium AZ31 alloy, one based on crystal plasticity and the other based on continuum plasticity. Crystal plasticity models are traditionally implemented as a computationally expensive nested FEM scheme [37 39], although less computationally demanding self-consistent approaches are possible [32, 40, 42]. In the field of continuum plasticity, constitutive equations were developed by modifying equations for kinematic hardening, either by anisotropic yield function [9, 12, 43] or by involving multiple yield surfaces [37, 44, 45]. Several rheological models dealing with asymmetric hysteresis nonlinearities in smart material based sensors and actuators have used a modified Prandtl-Ishlinskii hysteresis operator, where the classical symmetric play operator is replaced with a complex nonlinear operator [46, 47], two asymmetric operators [48] or a nonlinear input function [49]. Nagode et al. [50-52] developed several rheological models based on Prandtl-Ishlinskii operators for the simulation of the response of isotropic materials to thermo-mechanical fatigue. The advantages of a Prandtl-Ishlinskii rheological model are multifaced. First a Prandtl-Ishlinskii rheological model is multilinear, fast and easy to use. It consists of serially connected spring-slider units, that are able to model nonlinear material behaviour with an accuracy proportional to the number of spring-slider units. Second, a Prandtl-Ishlinskii rheological model is based directly on raw test data from low cycle fatigue (LCF) testing. In this paper a new asymmetric Prandtl-Ishlinskii rheological model has been developed for predicting the response of magnesium AZ31 alloy to arbitrary uniaxial cyclic loading under isothermal conditions. It is based on observations obtained from strain controlled uniaxial cyclic loading tests at constant and variable strain amplitudes and room temperature. Pure elasto-plastic behaviour is assumed. The advantages of a Prandtl-Ishlinskii rheological model are the description of arbitrary cyclic loading histories, robustness, short computational times and precise stress-strain simulations which are all important factors in fatigue life estimation techniques for complex mechanical components. 


\section{Experiments}

\subsection{Material and experimental procedure}

To study the material behaviour under large strain cyclic loading, a $2 \mathrm{~mm}$ thick hot rolled magnesium AZ31 alloy sheet $(96 \% \mathrm{Mg}, 3 \% \mathrm{Al}, 1 \% \mathrm{Zn})$, provided by Goodfellow Cambridge Ltd., was used. The wrought magnesium AZ31 alloy was received as a rectangular board, from which non-standard shaped specimens were cut along the rolling direction using a CNC waterjet cutting machine with no further surface treatment. The geometry and dimensions of the specimens are shown in Figure 1. Uniaxial strain controlled cyclic loading tests were

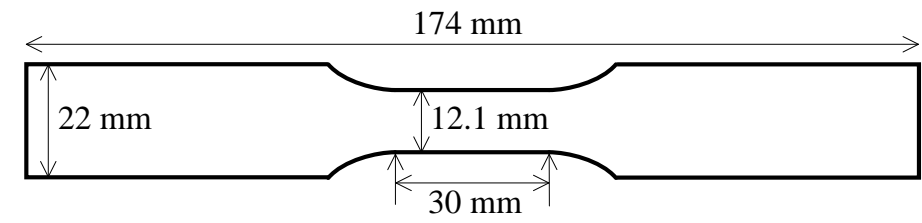

Figure 1: Geometry and dimensions of the cyclic test specimen.

carried out at room temperature using an MTS servo hydraulic testing machine. The total strain amplitude varied from $-1.5 \%$ to $1.5 \%$ true strain. The strain was measured directly on the specimen on a gauge length of $30 \mathrm{~mm}$ using an MTS extensometer. To provide a similar test speed for all considered strain amplitudes, load frequencies were chosen depending on the applied strain amplitudes as given in Table1. Load frequencies were chosen with respect to the experimental data presented in [22, 23].

Table 1: Load frequencies chosen for cyclic loading experiments at different strain amplitudes.

\begin{tabular}{lcccc}
\hline Maximal strain amplitude $[\%]$ & $\leq 0.50$ & 0.75 & 1.00 & $\geq 1.25$ \\
\hline Strain ratio $[\mathrm{Hz}]$ & 0.5 & 0.3 & 0.2 & 0.1 \\
\hline
\end{tabular}

\subsection{Measurement technique}

The specimen cut from the magnesium alloy plate required additional support to prevent buckling during compression under large strain cyclic loading ([9, 11, 12, 20, 53]). The anti- 
buckling support was a modification of the solutions presented in [12, 43]. The specimen was mounted without clearance between two I-shaped blocks made of high strength steel that were clamped with four bolts to prevent out of plane buckling of the specimen (see Figure 2). No prestress was imposed on the specimen due to the anti-buckling support. A

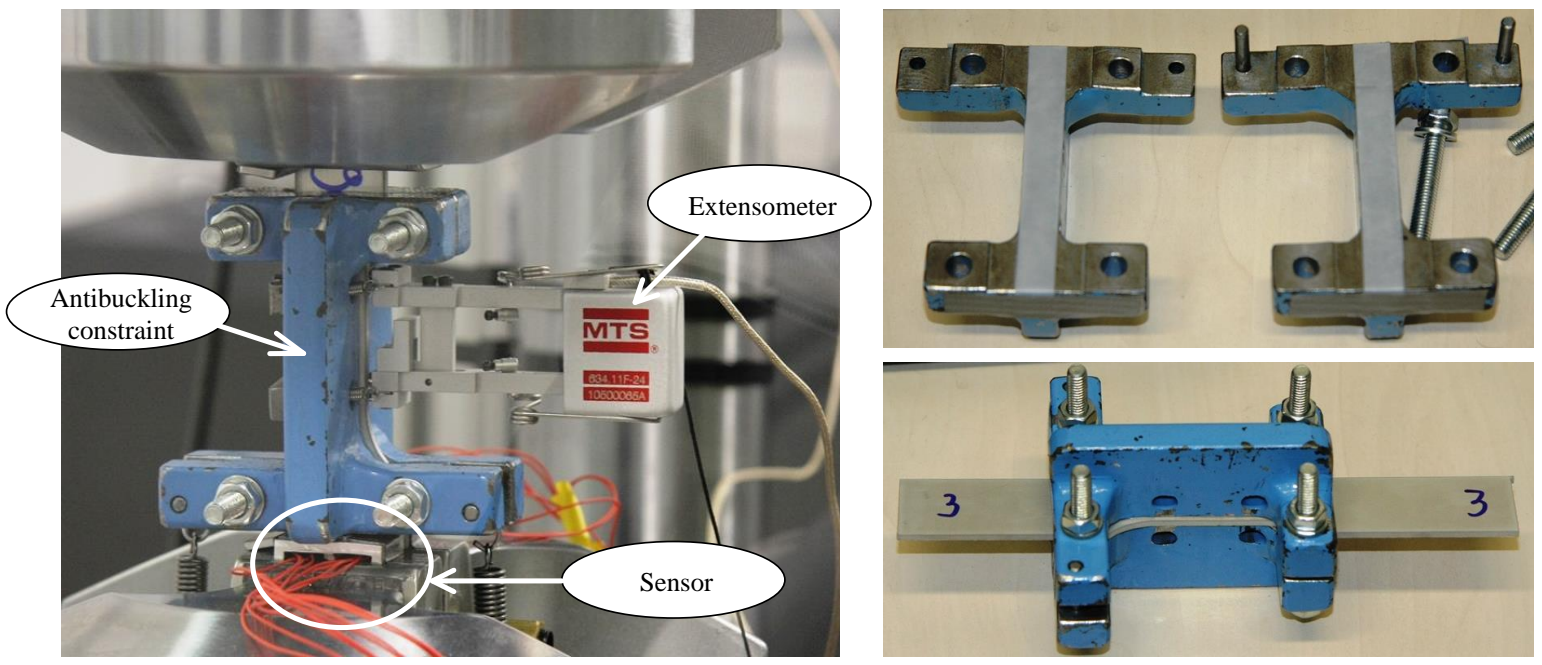

Figure 2: Specimen mounted on the MTS testing system with anti-buckling support, friction force sensing system, positioning springs and MTS extensometer. On the right side the I-shaped blocks of the anti-bucklig support with $0.1 \mathrm{~mm}$ thick PTFE foil are shown and a specimen mounted into the antibuckling support.

layer of $0.1 \mathrm{~mm}$ thick PTFE foil was placed between the specimen and both I-shaped blocks to minimize the effects of friction. A special sensor was developed to obtain the actual friction force continuously during cyclic testing. Namely, when the specimen is subjected to a compressive load higher than its buckling strength it causes a friction force between the specimen and the anti-buckling support. The friction force causes the I-shaped blocks to press onto the sensor, placed beneath them (see Figure 2). From the deformation of the sensor the friction force is obtained directly and continuously through the testing procedure. 


\section{Experimental results}

\subsection{Effect of friction}

The total measured compression force is higher due to the effect of friction between the specimen and anti-buckling support as presented in Table 2 and graphically in Figure 3 during cyclic loading test with a strain amplitude of $1.25 \%$ true strain. The results show that the correction due to friction is not considerable, nevertheless the compression force was corrected for all test results.

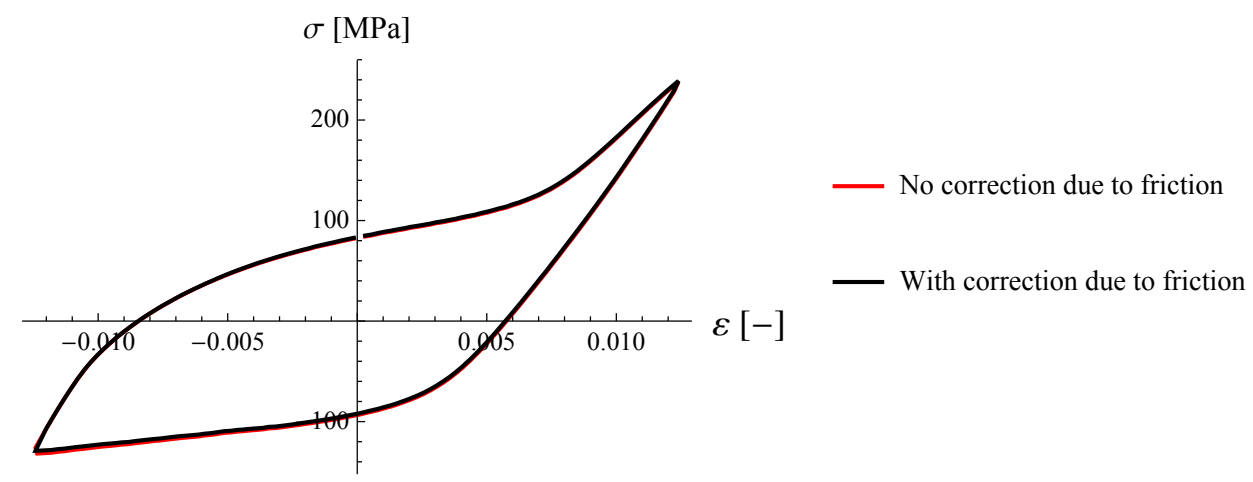

Figure 3: Stress-strain response with correction due to friction vs no correction due to friction.

\subsection{Reference hysteresis loops}

The specimens were subjected to uniaxial cyclic loading in the rolling direction at constant and variable strain amplitudes. The constant strain amplitude loadings are listed in Table 2, For each loading a reference hysteresis loop, shown in Figure 4, corresponds to a reference load cycle listed in Table 2 occuring at the half life of each specimen. Here, the half life is defined as approximately half the number of load cycles until the material fails. Variation in the minimum and maximum measured stresses with the number of load cycles is shown in Figure 5. It is observed that when subjected to cyclic loading at room temperature, magnesium AZ31 alloy exhibits a complex behaviour that is not symmetric in tension and compression as was already documented in [9, 11, 12, 20, 23]. The unusual S-shaped ascending part of the hysteresis loop gets more pronounced for cyclic loading with 
Table 2: Measured values of minimum stress in the reference hysteresis loops for all considered constant strain amplitudes and corrected values due to friction.

\begin{tabular}{lccccc}
\hline Strain amplitude [\%] & 0.25 & 0.5 & 0.75 & 1.00 & 1.25 \\
\hline $\begin{array}{l}\text { Number of load } \\
\text { cycles to failure }\end{array}$ & 9377 & 953 & 421 & 197 & 197 \\
$\begin{array}{l}\text { Reference load } \\
\text { cycle }\end{array}$ & 4700 & 480 & 210 & 99 & 99 \\
Measured minimal & & & & & \\
stress [MPa] & -86.2 & -109.1 & -118.9 & -123.9 & -131.8 \\
Corrected minimal & & & & & \\
stress [MPa] & -84.9 & -107.8 & -116.6 & -121.4 & -129.0 \\
\hline
\end{tabular}

larger strain amplitudes.

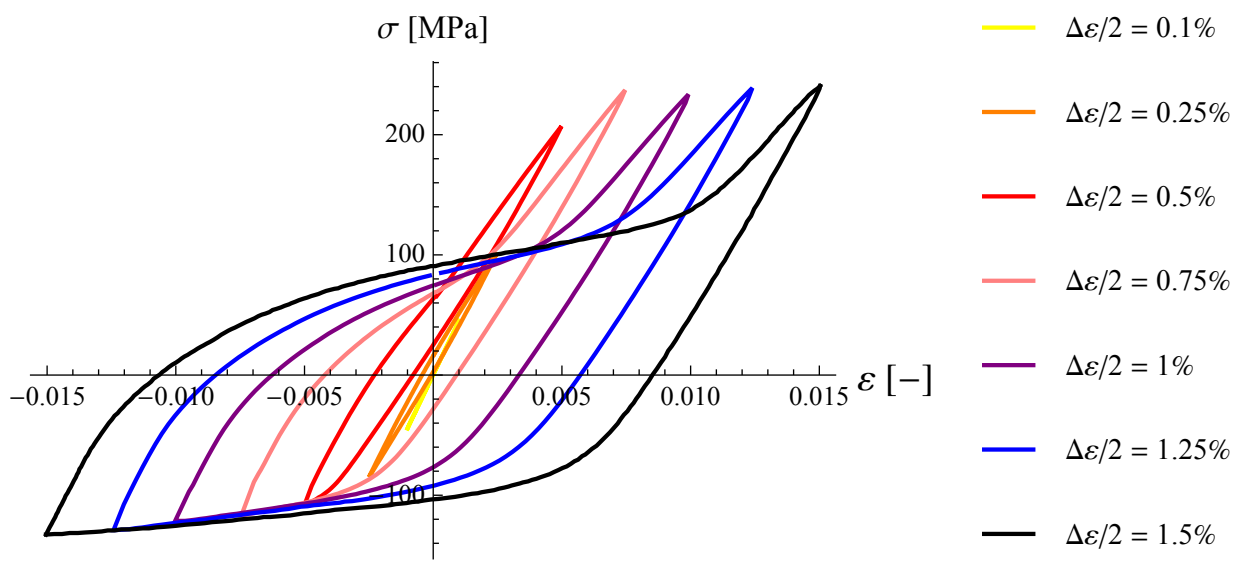

Figure 4: Reference hysteresis loops obtained by uniaxial cyclic loading.

Additionally, two variable strain amplitude loading tests with a maximum amplitude of $1.5 \%$ true strain were conducted. Block loadings with variable strain amplitude are listed in Table 3. The strain history corresponding to block loading A is similar to that presented in [25] and is shown in Figure 6a. The reference stress-strain response to block loading A is 


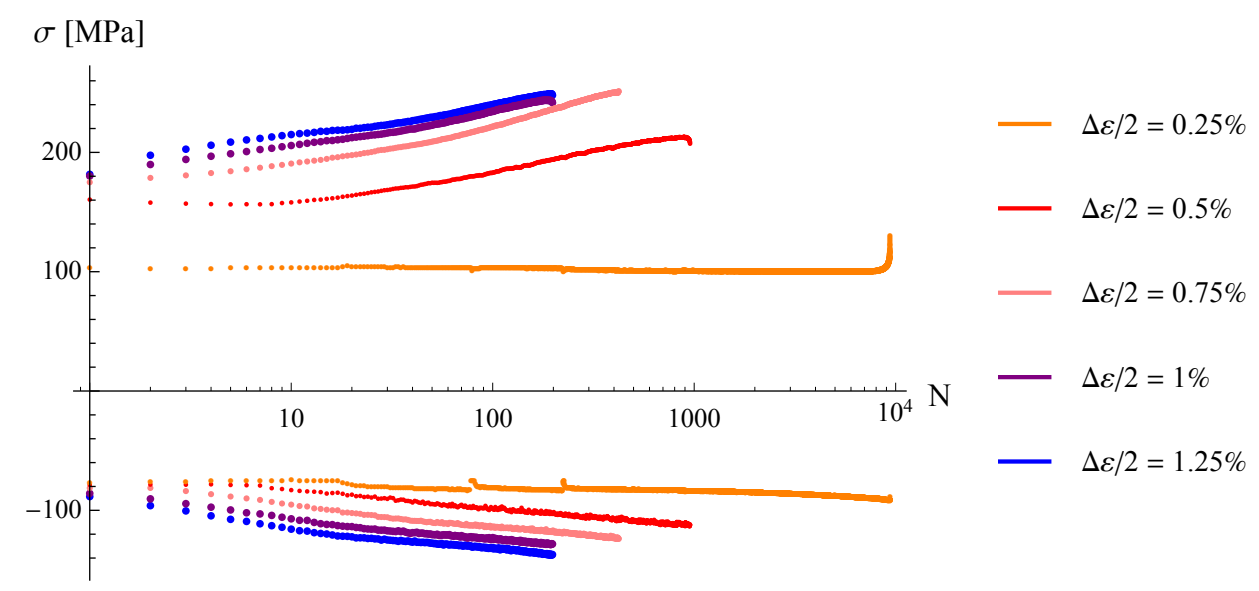

Figure 5: Minimum and maximum measured stresses as a function of the number of load cycles for constant amplitude loadings.

Table 3: Measured values of minimum stress in the reference block loadings A and B and corrected values due to friction.

\begin{tabular}{lcc}
\hline Block loading & A & B \\
\hline Maximal strain amplitude [\%] & 1.50 & 1.50 \\
Number of block loadings to failure & 29 & 13 \\
Reference block loading & 14 & 6 \\
Measured minimal stress [MPa] & -136.5 & -140.1 \\
Corrected minimal stress [MPa] & -133.2 & -140.1 \\
\hline
\end{tabular}

shown in Figure 6b. The major loop of this response was chosen as the reference hysteresis loop for a strain amplitude of $1.5 \%$ true strain and is depicted in Figure 4. 


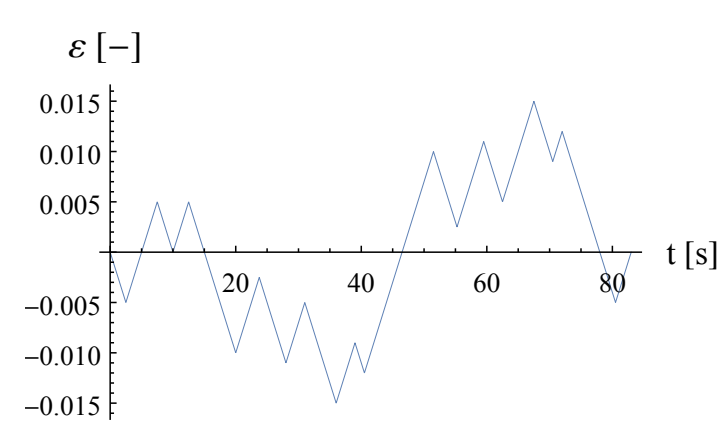

(a)

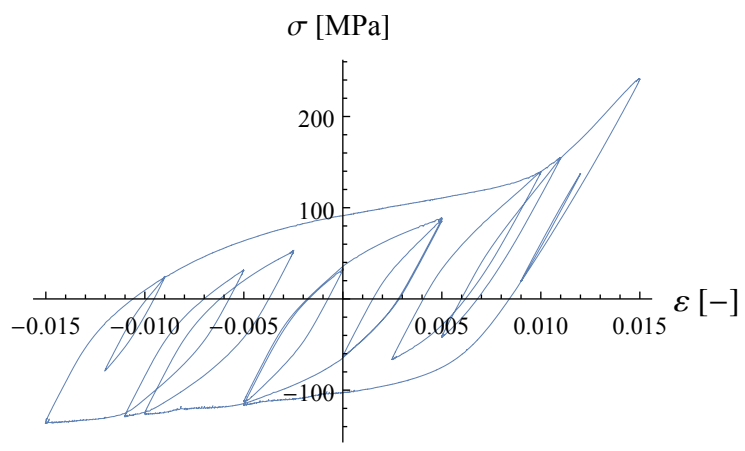

(b)

Figure 6: (a) Strain history corresponding to block loading A with (b) reference stress-strain response.

Block loading $\mathrm{B}$ was conducted to check the material response in strain ranges not covered in block loading $\mathrm{A}$ and to check the behaviour in the case of multiple nested minor loops. The strain history corresponding to block loading B is presented in Figures 7a and 8a. The reference stress-strain response to block loading B is shown in Figures $7 \mathrm{~b}$ and $8 \mathrm{~b}$, Here, the signal and the response are separated into two parts for clearer graphical presentation.

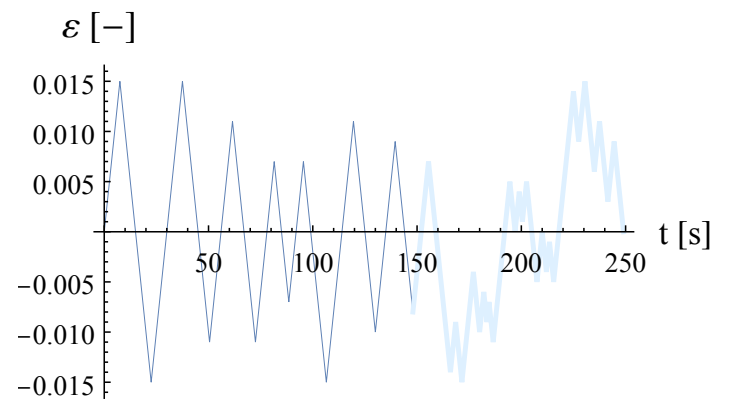

(a)

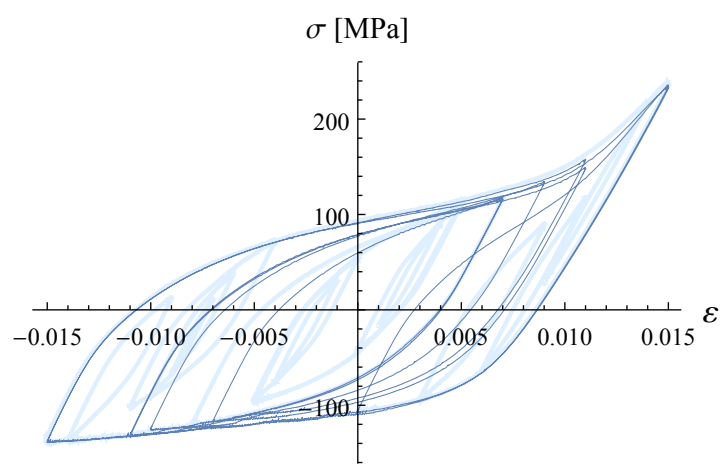

(b)

Figure 7: (a) Strain history corresponding to block loading B with (b) reference stress-strain response. The first part is highlighted. 


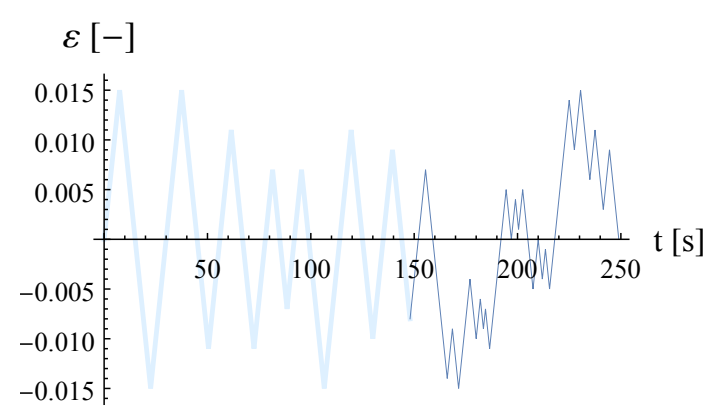

(a)

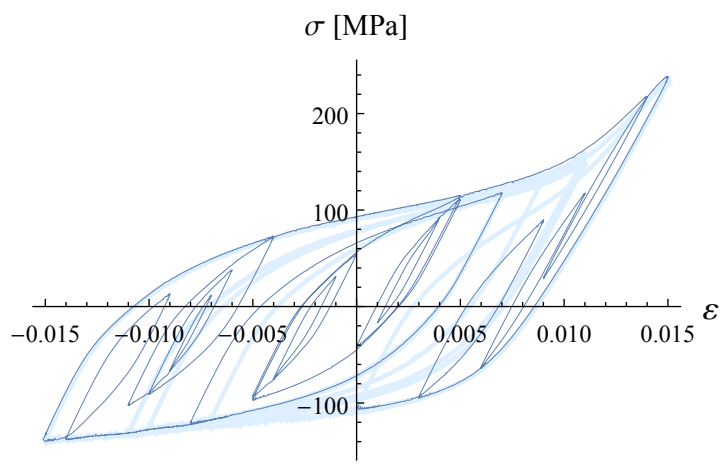

(b)

Figure 8: (a) Strain history corresponding to block loading B with (b) reference stress-strain response. The second part is highlighted.

\section{Material model for cyclic behaviour of magnesium AZ31 alloy}

The proposed rheological model for the cyclic behaviour of magnesium AZ31 alloy is based on the Prandtl-Ishlinskii hysteresis operator and the rheological model presented in [50]. The Prandtl-Ishlinskii modelling approach is based on the linear weighted superposition of many elementary play operators with different initial values [46]. If strain is the controlled variable it is convenient to formulate a Prandtl-Ishlinskii rheological model as a parallel connection of $n_{q}$ spring-slider sequences as depicted in Figure 9 .
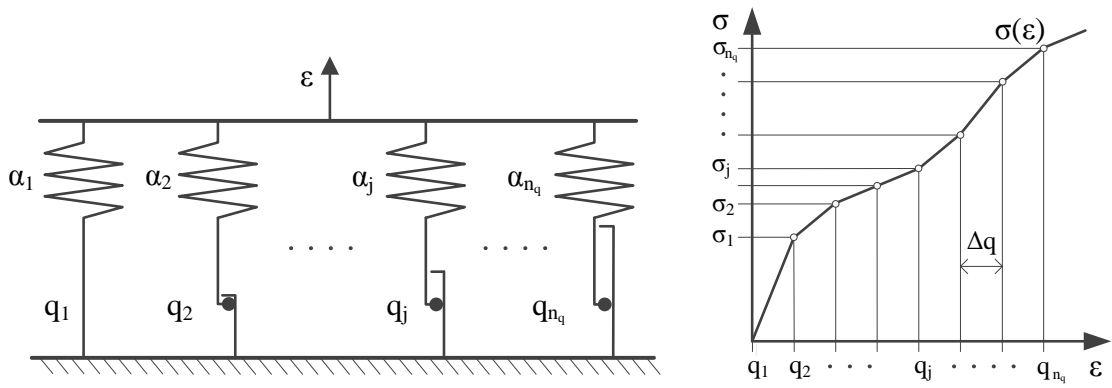

Figure 9: Rheological model with parallel connected spring-slider segments. 
The total strain $\varepsilon\left(t_{k}\right)$ is expressed as the sum of elastic spring strain $\varepsilon_{\alpha j}\left(t_{k}\right)$ and plastic slider strain $\varepsilon_{q j}\left(t_{k}\right)$ in the $j$-th spring-slider segment, hence

$$
\varepsilon\left(t_{k}\right)=\varepsilon_{q j}\left(t_{k}\right)+\varepsilon_{\alpha j}\left(t_{k}\right), \quad k=1, \ldots, n, \quad j=1, \ldots, n_{q}
$$

for each time step $t_{k}, 0<t_{1}<t_{2}<\cdots<t_{n}$. The slider strain $\left|\varepsilon_{q j}\left(t_{k}\right)\right|$ can never exceed the fictive yield strain $q_{j}$. In the classical Prandtl-Ishlinskii rheological model, where hysteresis loops are symmetrical, spring strain $\varepsilon_{\alpha j}\left(t_{k}\right)$ is defined by a play operator with a general initial value [35, 54 ]

$$
\varepsilon_{\alpha j}\left(t_{k}\right)=\max \left\{\varepsilon\left(t_{k}\right)-q_{j}, \min \left\{\varepsilon\left(t_{k}\right)+q_{j}, \varepsilon_{\alpha j}\left(t_{k-1}\right)\right\}\right\}
$$

The total stress $\sigma\left(t_{k}\right)$ in each time step $t_{k}, k=1, \ldots, n$, is given by the Prandtl-Ishlinskii superposition operator as [46, 54]

$$
\sigma\left(t_{k}\right)=\sum_{j=1}^{n_{q}} \sigma_{j}\left(t_{k}\right)=\sum_{j=1}^{n_{q}} \alpha_{j} \varepsilon_{\alpha j}\left(t_{k}\right), \quad k=1, \ldots, n
$$

where $\sigma_{j}\left(t_{k}\right)=\alpha_{j} \varepsilon_{\alpha j}\left(t_{k}\right)$ is the stress in the $j$-th spring-slider segment and $\alpha_{j}$ represents the $j$-th Prandtl density obtained from a stress-strain cyclic curve (see [50, 51]).

\subsection{Simulating constant strain amplitude loading with Prandtl-Ishlinskii operators}

Experimental measurements of the response of magnesium AZ31 alloy to uniaxial cyclic loading show an asymmetric hysteresis loop which cannot be achieved by the symmetrical play operator defined in (2). Therefore, the ascending and descending branches of the hysteresis loops are modelled separately using the modified Prandtl-Ishlinskii approach. A one side play operator for the spring strain $\varepsilon_{U \alpha j}\left(t_{k}\right)$ is suggested for the ascending part of the hysteresis loop

$$
\varepsilon_{U \alpha j}\left(t_{k}\right)=\max \left\{\varepsilon\left(t_{k}\right)-\varepsilon_{0}-q_{U j}, \min \left\{\varepsilon\left(t_{k}\right)-\varepsilon_{0}, \varepsilon_{U \alpha j}\left(t_{k-1}\right)\right\}\right\}
$$

and analogically $\varepsilon_{T \alpha j}\left(t_{k}\right)$ for the descending part of the hysteresis loop

$$
\varepsilon_{T \alpha j}\left(t_{k}\right)=\max \left\{\varepsilon\left(t_{k}\right)-\varepsilon_{0}, \min \left\{\varepsilon\left(t_{k}\right)-\varepsilon_{0}+q_{T j}, \varepsilon_{T \alpha j}\left(t_{k-1}\right)\right\}\right\}
$$


where $\varepsilon_{0}$ represents the strain at the point of initiation of an active branch. In equations (4) and (5) index $U$ stands for an untwinning plastic deformation mechanism and index $T$ stands for a twinning plastic deformation mechanism which are prevalent in the ascending and descending branches of the hysteresis loop, respectively.

Prandtl densities $\alpha_{i j}$ are calculated from the stress-strain curves of each deformation mechanism $i \in\{U, T\}$ for all spring-slider segments $j=1, \ldots, n_{q}$. Stress-strain curves for deformation mechanisms $U$ and $T$ are obtained with translation of the ascending and descending branches, respectively, of all reference hysteresis loops into the origin. Descending branches are also reflected through the origin to the first quadrant. The resulting stressstrain curves are depicted in Figure 10 with solid lines for deformation mechanism $U$ and with dashed lines for deformation mechanism $T$. It can be seen that the shape of the stress-strain curve for deformation mechanism $U$ varies with strain amplitude $\Delta \varepsilon / 2$. To enable correct simulation of hysteresis loops with variable strain amplitude Prandtl densities $\alpha_{i j}\left(\varepsilon_{\max }\right)$ are calculated for all possible values of strain amplitude $\varepsilon_{\max }=\Delta \varepsilon / 2$. Prandtl densities for any unmeasured values of strain amplitude are calculated by linear interpolation of the measured values.

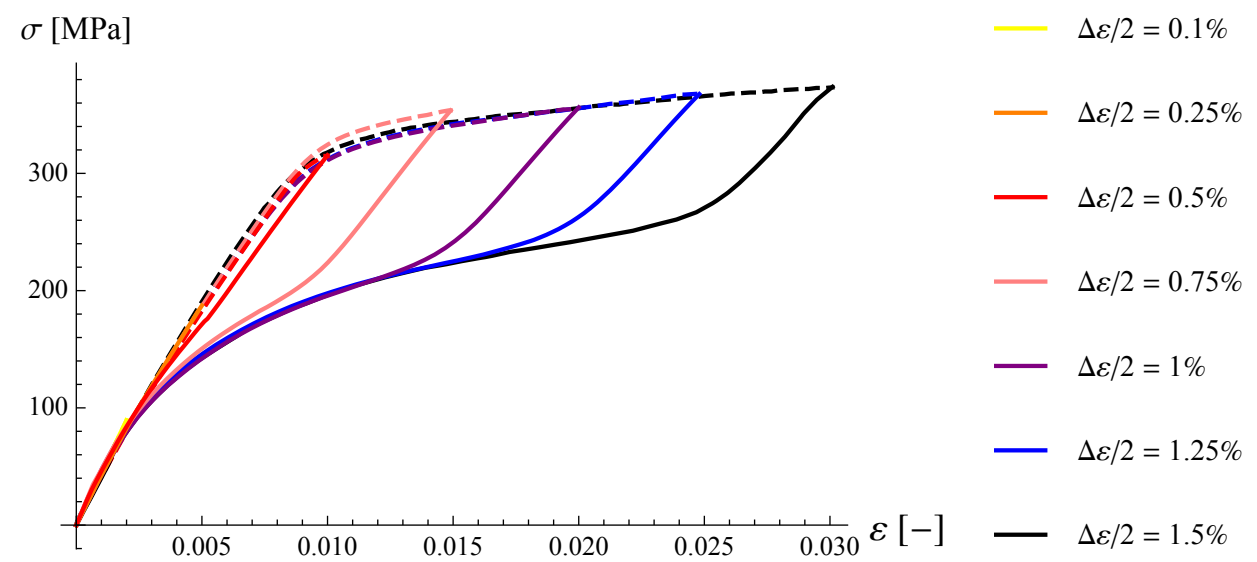

Figure 10: Stress-strain curves for deformation mechanisms $U$ (solid lines) and $T$ (dashed lines) for different strain amplitude loadings. 
The maximum strain range of the rheological model is divided into $n_{q}$ intervals by fictive yield strains $q_{i j}=\left\{q_{i 1}, \ldots, q_{i n_{q}}\right\}$ for each deformation mechanism $i \in\{U, T\}$. The associated fictive yield stresses $\sigma_{i j}\left(\varepsilon_{\max }\right)$ are determined for each $q_{i j}$ by a stress-strain curve for the strain amplitude $\varepsilon_{\max }$. If fictive yield strains $q_{i j}, j \in\left\{1, \ldots, n_{q}\right\}$, are dispersed equidistantly between zero and the maximum expected strain range for each deformation mechanism $i \in\{U, T\}$, Prandtl densities $\alpha_{i j}\left(\varepsilon_{\max }\right)$ for strain amplitude $\varepsilon_{\max }$ are calculated as [50, 51]

$$
\alpha_{i j}\left(\varepsilon_{\max }\right)=\frac{1}{\Delta q}\left(\sigma_{i j+1}\left(\varepsilon_{\max }\right)-2 \sigma_{i j}\left(\varepsilon_{\max }\right)+\sigma_{i j-1}\left(\varepsilon_{\max }\right)\right),
$$

where $\Delta q$ represents the fictive yield strain class width and $\sigma_{i 0}\left(\varepsilon_{\max }\right)=\sigma_{i 1}\left(\varepsilon_{\max }\right)=0$ for every $i \in\{U, T\}$. For non equidistantly dispersed fictive yield strains, $\alpha_{i j}\left(\varepsilon_{\max }\right)$ is recursively defined as 52 .

$$
\alpha_{i j}\left(\varepsilon_{\max }\right)=\frac{1}{q_{j+1}-q_{j}}\left(\sigma_{i j+1}\left(\varepsilon_{\max }\right)-\sum_{k=1}^{j-1} \alpha_{i k}\left(\varepsilon_{\max }\right)\left(q_{j+1}-q_{k}\right)\right) .
$$

The stress-strain curve for deformation mechanism $i \in\{U, T\}$ and the strain amplitude $\varepsilon_{\max }$ determines the current stress $\sigma_{i}\left(t_{k}\right)$ in deformation mechanism $i$ by the PrandtlIshlinskii superposition operator [46, 50]

$$
\sigma_{i}\left(t_{k}\right)=\sum_{j=1}^{n_{q}} \alpha_{i j}\left(\varepsilon_{\max }\right) \varepsilon_{i \alpha j}\left(t_{k}\right), \quad k=1, \ldots, n, \quad i \in\{U, T\}
$$

where $\alpha_{i j}\left(\varepsilon_{\max }\right)$ represents the $j$-th Prandtl density for deformation mechanism $i$ and the strain amplitude $\varepsilon_{\max }$. The total current stress $\sigma\left(t_{k}\right)$ in the hysteresis loop is the sum of the stress $\sigma_{0}$ at initiation of the active deformation mechanism $i$ and the current stress $\sigma_{i}\left(t_{k}\right)$ in the active deformation mechanism $i$. Hence,

$$
\sigma\left(t_{k}\right)=\sigma_{i}\left(t_{k}\right)+\sigma_{0}, \quad k=1, \ldots, n, \quad i \in\{U, T\}
$$

Presumably, for an initial state $\varepsilon(0)=0$ and $\sigma(0)=0$, the rheological model presented here assumes that the material follows a cyclic tension or compression curve when the current absolute maximum strain $\varepsilon_{\max }$ achieved in the current loading history is exceeded in tension or compression loading, respectively. Note that this is always true in the first time step. 
Cyclic curves are shown in Figure 11. Prandtl densities $\alpha_{U 0 j}$ for cyclic tension curves and Prandtl densities $\alpha_{T 0 j}$ for cyclic compression curves are calculated by equation (6) or (7) for every $j \in\left\{1, \ldots, n_{q}\right\}$, noting that they are not dependent on the strain amplitude $\varepsilon_{\max }$. The current stress $\sigma\left(t_{k}\right)$ for $i \in\{T 0, U 0\}$ is calculated by equations (8) and (9) where $\sigma_{0}=0$ and $\varepsilon_{0}=0$. The associated spring strains $\varepsilon_{T 0 \alpha j}$ and $\varepsilon_{U 0 \alpha j}$ are calculated for every $j \in\left\{1, \ldots, n_{q}\right\}$ by equations (4) and (5), respectively.

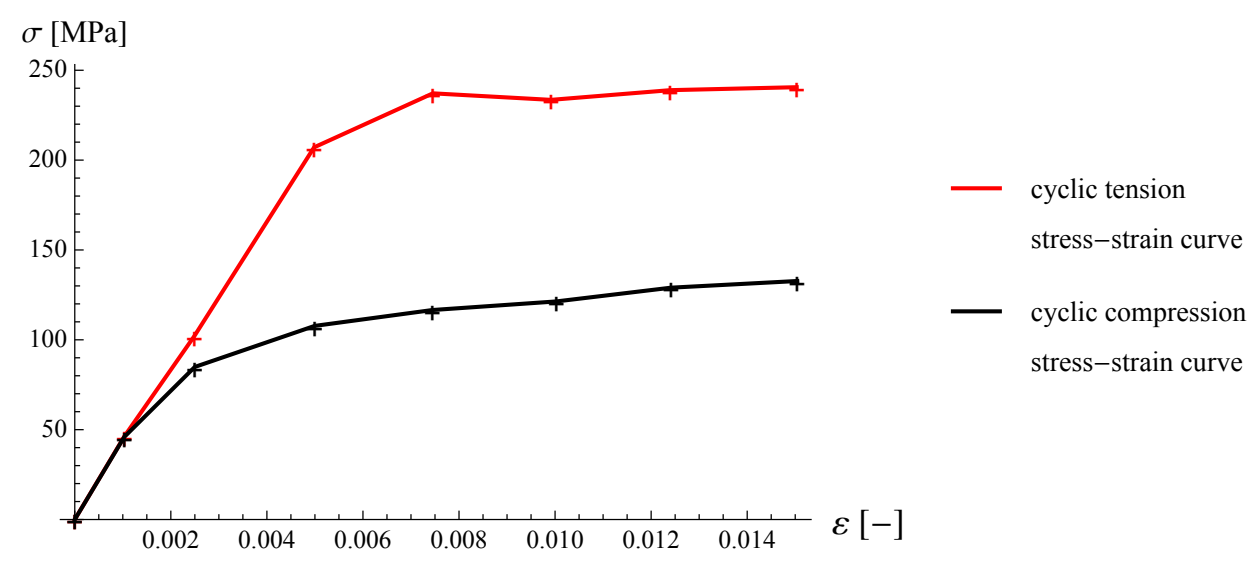

Figure 11: Cyclic stress-strain curves for cyclic loading in tensile and compressive directions.

\subsection{Simulating variable strain amplitude loading with Prandtl-Ishlinskii type operators}

In the case of variable strain amplitude loading, obtained the measurements depicted in Figures $6-8$ suggest that minor loops are in general symmetric yet can become asymmetric if large enough. It is also observed that the material obeys Madelung's memory rules [35] for major and minor hysteresis loops. Therefore, minor loops are modelled as symmetric hysteresis loops with one side play operators that are compliant with Madelung's memory rules [35]. Hence, the ascending and descending parts of a minor loop are modelled with the same one side play operator, (4) or (5), depending on the originating branch of the major loop. Switching between one side play operators (4) and (5) enables modelling of asymmetric minor loops. However it should be noted that compliance with Madelung's memory rules can not be guaranteed if operators are switched during simulation of a hysteresis loop. 
A minor loop originating on the ascending branch of the major loop at time step $t_{k}$ is modelled symmetrically in the ascending and descending parts with play operator (5), where $\varepsilon_{T \alpha j}\left(t_{k-1}\right)$ is set to zero for all values of $j$ and $\varepsilon_{0}$ is the strain at the point of initiation of the minor loop. Experimental measurements show that the shape of the descending branch is dependent on the value of initiation strain $\varepsilon_{0}$. It was observed that minor loops initiated in the deformation area between certain values of threshold strain $\varepsilon_{\text {twin }}\left(\varepsilon_{\max }\right)$ and $\varepsilon_{\max }$ become increasingly narrower with a greater stress range. The threshold $\varepsilon_{\text {twin }}\left(\varepsilon_{\max }\right)$ is defined on the descending branch of the reference hysteresis loop by the strain amplitude $\varepsilon_{\max }$ at a strain where the gradient of the descending branch falls to a predefined value of $E_{\text {twin. }}$. Due to the fact that the same stress-strain curve describes the descending branches of all measured reference hysteresis loops (see Figure 10), $\varepsilon_{\text {twin }}$ falls on the same spot on this curve for all values of $\varepsilon_{\max }$. A graphical presentation of $\varepsilon_{\text {twin }}$ is given in Figure 12. For small strain amplitudes (i.e. where insufficient gradient change is observed in the descending hysteresis branch) the threshold $\varepsilon_{\text {twin }}$ equals negative strain amplitude.

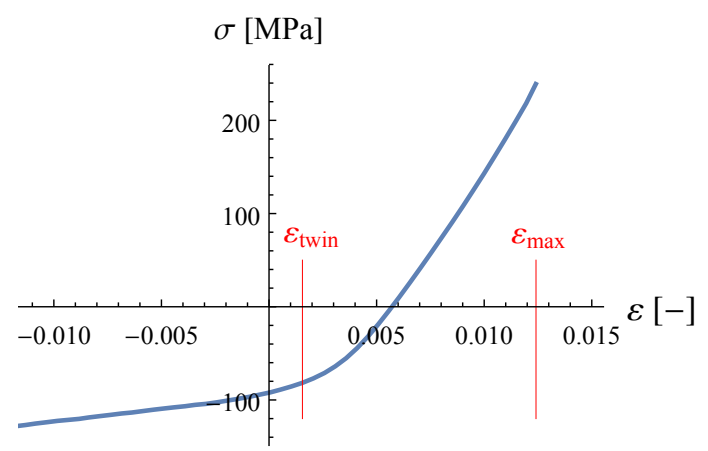

(a)

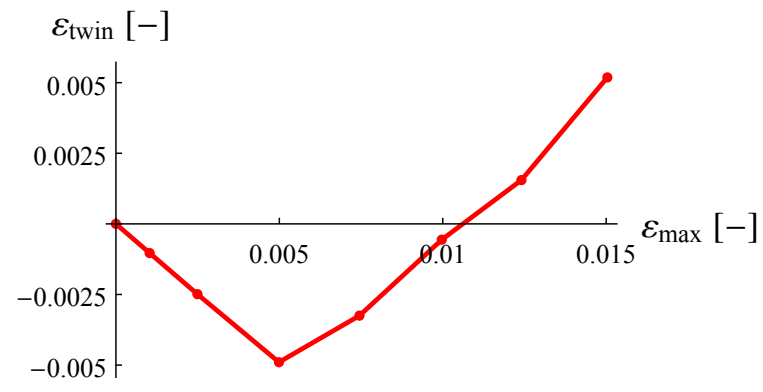

(b)

Figure 12: (a) Graphic depiction of the strain threshold $\varepsilon_{\text {twin }}$ for the descending branch of the reference hysteresis loop at strain amplitude $1.25 \%$. (b) Treshold $\varepsilon_{\text {twin }}$ for the reference hysteresis loops at all considered strain amplitudes.

For a minor loop initiated at $\varepsilon_{0}<\varepsilon_{\text {twin }}\left(\varepsilon_{\max }\right)$ on the ascending branch of the major loop, 
the current stress $\sigma\left(t_{k}\right)$ is defined by equations (8) and (9) as

$$
\sigma\left(t_{k}\right)=\sigma_{0}+\sum_{j=1}^{n_{q}} \alpha_{U j}\left(\varepsilon_{\max }\right) \varepsilon_{T \alpha j}\left(t_{k}\right), \quad k=1, \ldots, n
$$

where $\sigma_{0}$ represents stress at the initiation of the minor loop and $\alpha_{U j}\left(\varepsilon_{\max }\right)$ represents Prandtl densities for active deformation mechanism $U$ and current maximum absolute strain $\varepsilon_{\max }$. For a minor loop with $\varepsilon_{0}>\varepsilon_{\text {twin }}\left(\varepsilon_{\max }\right)$, the current stress $\sigma\left(t_{k}\right)$ is defined by nonlinear interpolation between $\sigma_{1}$, the stress calculated using Prandtl densities for deformation mechanism $U$, and $\sigma_{2}$, the stress calculated using Prandtl densities for deformation mechanism $T$. Hence,

$$
\begin{aligned}
\sigma_{1}\left(t_{k}\right) & =\sum_{j=1}^{n_{q}} \alpha_{U j}\left(\varepsilon_{\max }\right) \varepsilon_{T \alpha j}\left(t_{k}\right), \\
\sigma_{2}\left(t_{k}\right) & =\sum_{j=1}^{n_{q}} \alpha_{T j}\left(\varepsilon_{\max }\right) \varepsilon_{T \alpha j}\left(t_{k}\right), \\
\sigma\left(t_{k}\right) & =\sigma_{1}\left(t_{k}\right)\left(1-c^{f}\right)+\sigma_{2}\left(t_{k}\right) c^{f}+\sigma_{0},
\end{aligned}
$$

where the interpolation coefficient $c$ equals

$$
c=\left(\varepsilon_{0}-\varepsilon_{\text {twin }}\left(\varepsilon_{\max }\right)\right) /\left(\varepsilon_{\max }-\varepsilon_{\text {twin }}\left(\varepsilon_{\max }\right)\right)
$$

and the interpolation exponent $f$ is set at a predefined value which gives the descending branch a shape that best represents the measured data. In the case where $f$ equals 1 , the equation (13) represents linear interpolation. Figure 13 graphically illustrates modelling of minor loops originating on the ascending branch of the major loop.

A minor loop originating on the descending branch of the major loop at an initial strain $\varepsilon_{0}$ is modelled using a play operator (4), where $\varepsilon_{U \alpha j}\left(t_{k-1}\right)$ is set to zero for all values of $j$. Experimental measurements show that the shape of the ascending branch of a minor loop originating on a descending branch of the major loop matches that of an ascending branch of a reference hysteresis loop with the same strain range as will be shown in Section 


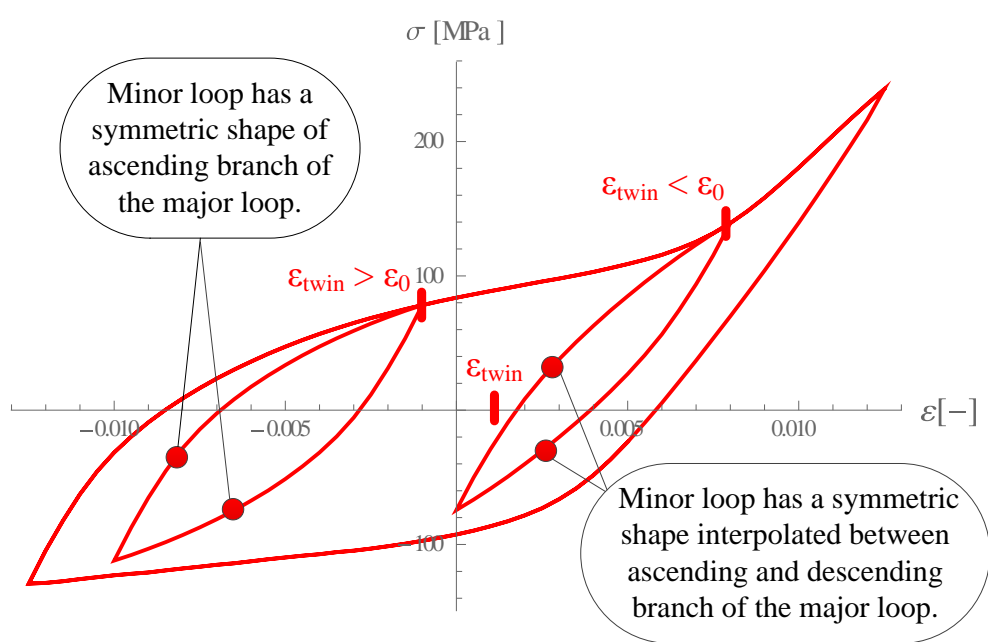

Figure 13: Modelling the shape of minor loops originating on the ascending part of the major loop depending on the value of initiation strain $\varepsilon_{0}$ of a minor loop.

5. Consequently, the current stress $\sigma\left(t_{k}\right)$ is defined by equations (8) and (9) as

$$
\sigma\left(t_{k}\right)=\sigma_{0}+\sum_{j=1}^{n_{q}} \alpha_{U j}(\Delta \varepsilon / 2) \varepsilon_{U \alpha j}\left(t_{k}\right), \quad k=1, \ldots, n
$$

where $\sigma_{0}$ represents stress at initiation of a minor loop and $\alpha_{U j}(\Delta \varepsilon / 2)$ are Prandtl densities associated with the ascending branch of a reference hysteresis loop with strain amplitude $\Delta \varepsilon / 2=\left(\varepsilon_{\max }-\varepsilon_{0}\right) / 2$. The descending branch of such a minor loop is modelled using the same Prandtl densities as the ascending branch as long as the current strain $\varepsilon\left(t_{k}\right)$ stays below the threshold value $\varepsilon_{\text {twin }}\left(\varepsilon_{\max }\right)$. If on the ascending branch at some time step $t_{k}$, the current strain $\varepsilon\left(t_{k}\right)$ exceeds $\varepsilon_{\text {twin }}\left(\varepsilon_{\max }\right)$ and simultaneously the strain range of the minor loop exceeds the strain range for the symmetric response, then the descending branch follows the rules for minor loops originating on an ascending part of the major loop at an initial strain $\varepsilon_{0}>\varepsilon_{\text {twin }}\left(\varepsilon_{\max }\right)$, see equation $(13)$. The simulation of symmetric and asymmetric minor loops originating on the descending branch of the major loop is depicted in Figure 14. 


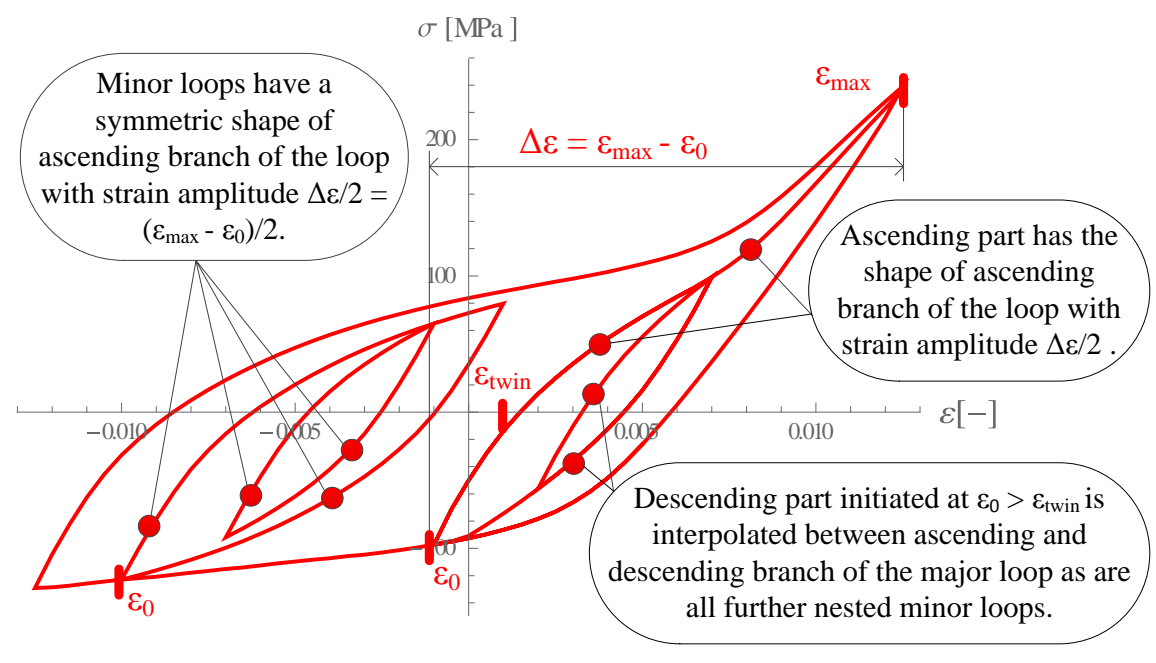

Figure 14: Modelling the shape of minor loops originating on the descending part of the major loop and transition from symmetric to asymmetric modelling of minor loops.

Implementation of the proposed Prandtl-Ishlinskii rheological model is explained in detail in Appendix A.

\section{Verification and discussion}

The proposed Prandtl-Ishlinskii rheological model is verified for several load cases which have been considered by both simulations and experiments using magnesium AZ31 alloy. The accuracy of the proposed rheological model is verified first by a simulation of constant strain amplitude loading at $R=-1$ for which measurements were obtained. Figure 15 shows that the simulation of $0.75 \%$ true strain amplitude loading at $R=-1$ clearly matches the measured response of the magnesium alloy. This shows that the proposed Prandtl-Ishlinskii model is correctly implemented for it is based on reference hysteresis loops obtained by constant amplitude loading tests. The second comparision, shown in Figure 15, depicts a simulated and measured reference hysteresis loop obtained by $0.75 \%$ true strain amplitude loading at $R=0$. Figure 15 shows that the shape of the measured hysteresis loop for $R=-1$ matches that for $R=0$, similar results being obtained by tension-compressiontension tests presented in [11]. This is not exactly true for the simulated response as can be 
seen in Figure 15. This is a result of the implementation which controls the shape of the simulated hysteresis branches by the value of the maximum absolute strain $\varepsilon_{\max }$, where $\varepsilon_{\max }$ is $1.5 \%$ for $0.75 \%$ true strain amplitude loading at $R=0$. The adequacy of the proposed Prandtl-Ishlinskii rheological model for simulating the response of the magnesium alloy to variable strain amplitude loading is further verified by data obtained from two separate block loadings. Figures 16, 17 and 18 show the performance of the proposed Prandtl-Ishlinskii model on the general strain history.
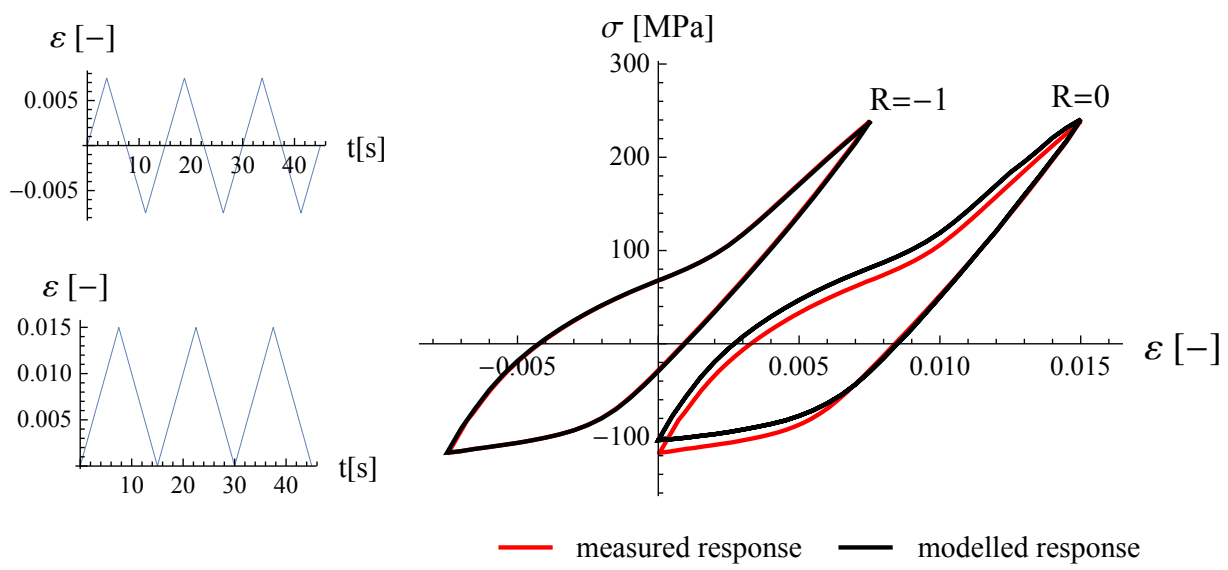

Figure 15: Comparison between simulated and measured response to constant $0.75 \%$ true strain amplitude loading at $R=-1$ and $R=0$.

In Figure 16 there is a clear agreement between the simulated and measured major loop due to the fact that the measured major loop from reference block loading $\mathrm{A}$ is incorporated in the proposed model as a reference hysteresis loop for a strain amplitude of $1.5 \%$ true strain. Hysteresis loops of the alloy under constant strain amplitude loading at $R=-1$ match those at $R=0$ (see Figure 15) are also observed for variable strain amplitude loading. The shape of the ascending branch of a minor loop originating at $\varepsilon_{0}$ on the descending branch of the major loop matches that of a hysteresis loop with strain amplitude $\left(\varepsilon_{\max }-\varepsilon_{0}\right) / 2$. Regarding minor loops it was also observed that the shape is in most cases symmetrical yet descending 
branches start transitioning from the shape of ascension branch to that of the descending branch of the major loop around a deformation threshold $\varepsilon_{\text {twin }}\left(\varepsilon_{\max }\right)$, which is defined for all possible $\varepsilon_{\max }$ by parameter $E_{\text {twin }}$ (see Section 4.2). This transition is modelled by a nonlinear interpolation of associated Prandtl densities. The interpolation exponent $f$ together with parameter $E_{\text {twin }}$ control the shape of minor loops in the strain area between strain threshold $\varepsilon_{\text {twin }}$ and maximum strain $\varepsilon_{\max }$. Values which yield the optimum fit for magnesium AZ31 alloy were determined as $f=2$ and $E_{\text {twin }}=9000 \mathrm{MPa}$. From experimental observations it can be concluded that a minor loop with a strain range less than $\varepsilon_{\max } / 2$ can be modelled as symmetrical independently of the value of $\varepsilon_{0}$. The results obtained by the proposed rheological model are very accurate, as judged by overall agreement between measured and simulated results exhibited in Figures 16, 17 and 18.

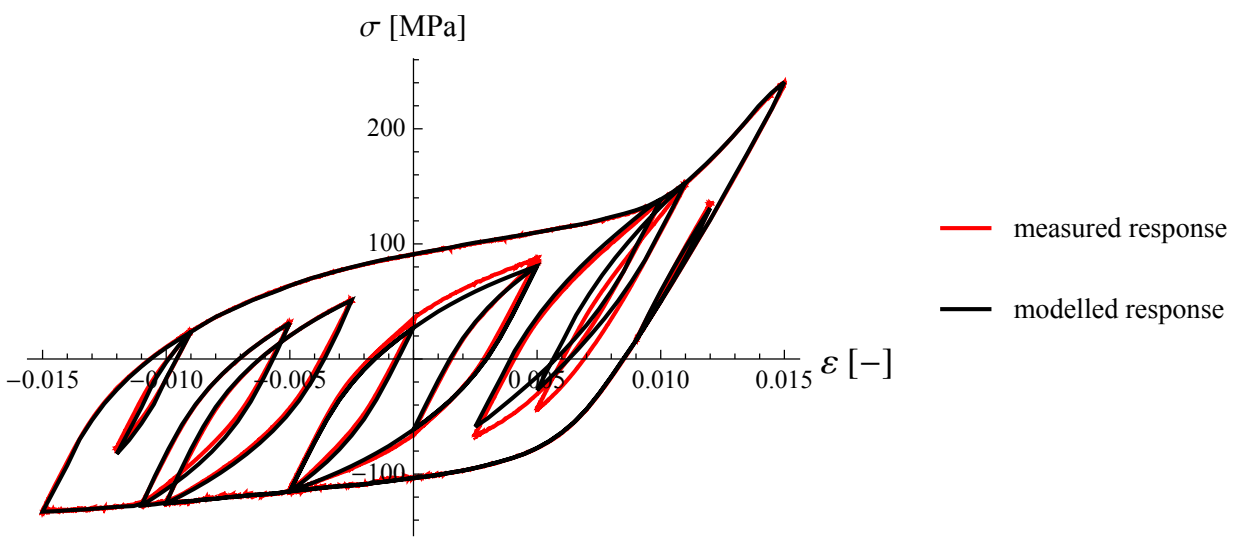

Figure 16: Comparison between the simulated and measured response to block loading A. The time-strain data for one load cycle is depicted in Figure 6 . 


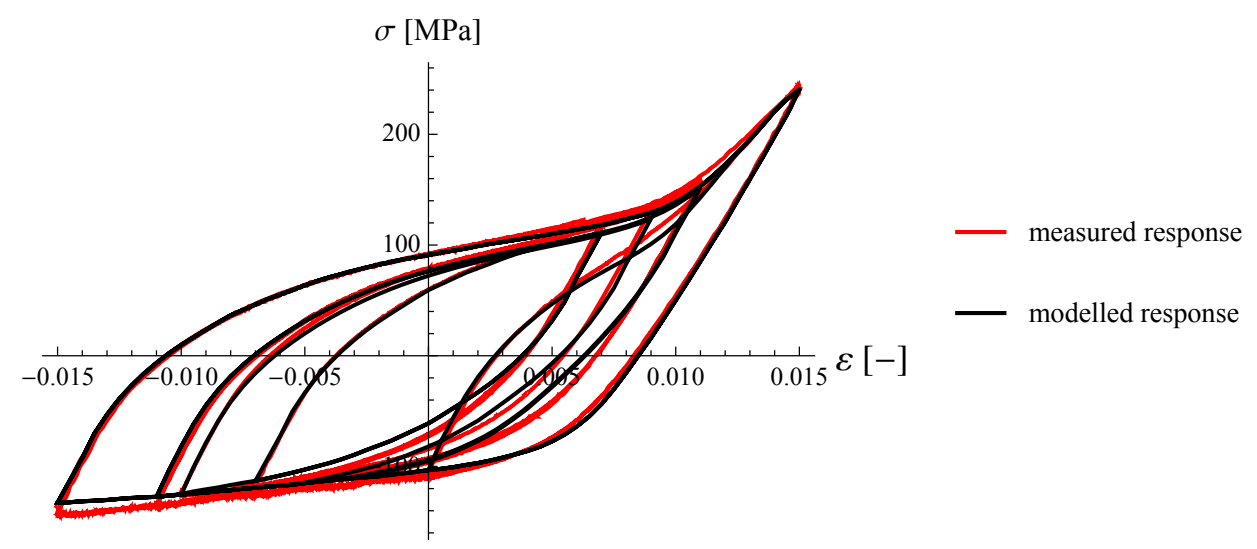

Figure 17: First part of the comparison between simulated and measured response to block loading B. The corresponding strain history is depicted in Figure 7 .

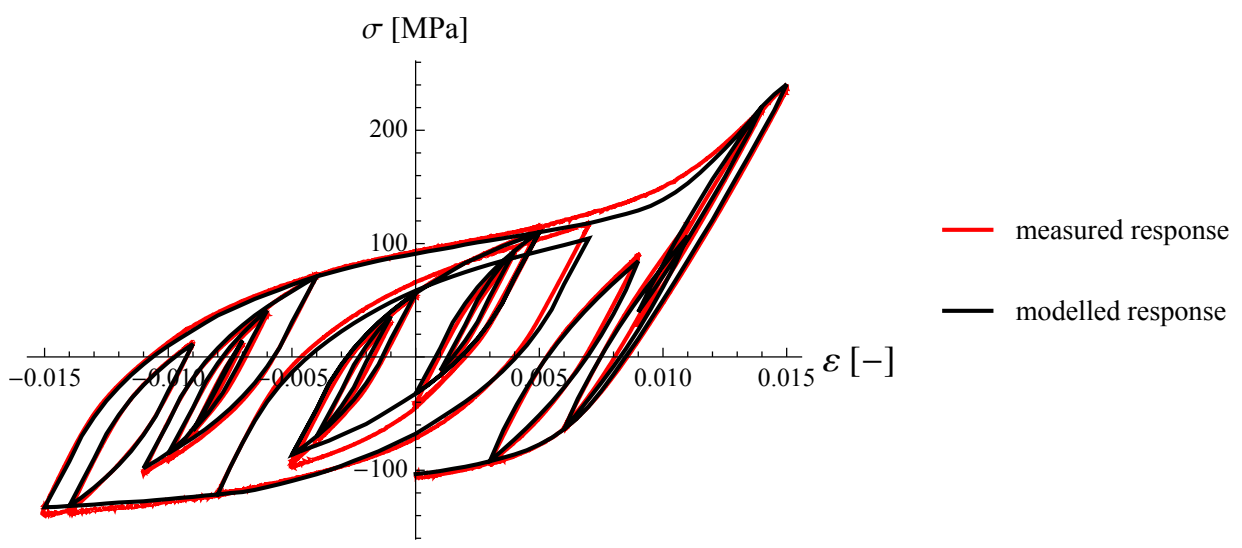

Figure 18: Second part of the comparison between simulated and measured response to block loading B. The corresponding strain history is depicted in Figure 8 .

In general, the accuracy of the presented Prandtl-Ishlinskii rheological model is dependent on both the number of reference hysteresis loops used to calibrate the model and the number of spring-slider segments used for multilinear representations of the reference hysteresis loops. The effect of the number of equidistantly dispersed spring-slider segments per reference hysteresis branch on the simulation quality of the presented asymmetric Prandtl- 
Ishlinskii operator is exhibited in Figure 19. However, a better result can be obtained by non-equidistantly dispersed spring-slider segments. The results presented in this paper are obtained by 30 equidistantly dispersed spring-slider segments for the largest reference hysteresis branch measured at constant $1.5 \%$ true strain amplitude loading. The minor reference hysteresis branches are modelled with proportionally less spring-slider segments. Note that the number of spring-slider segments determines the number of Prandtl densities that are calculated prior to the modelling of the stress-strain response and has no impact onto the computational efficiency of the Prandtl-Ishlinskii rheological model. Accurate simulation of the hysteresis loops during variable strain amplitude loading is very important for estimating fatigue life because even in the case of constant strain amplitude loading considerable scatter of the number of loading cycles to failure was observed [55 57]. Any additional scatter in the stress-strain simulation only increases the uncertainty of fatigue life predictions.

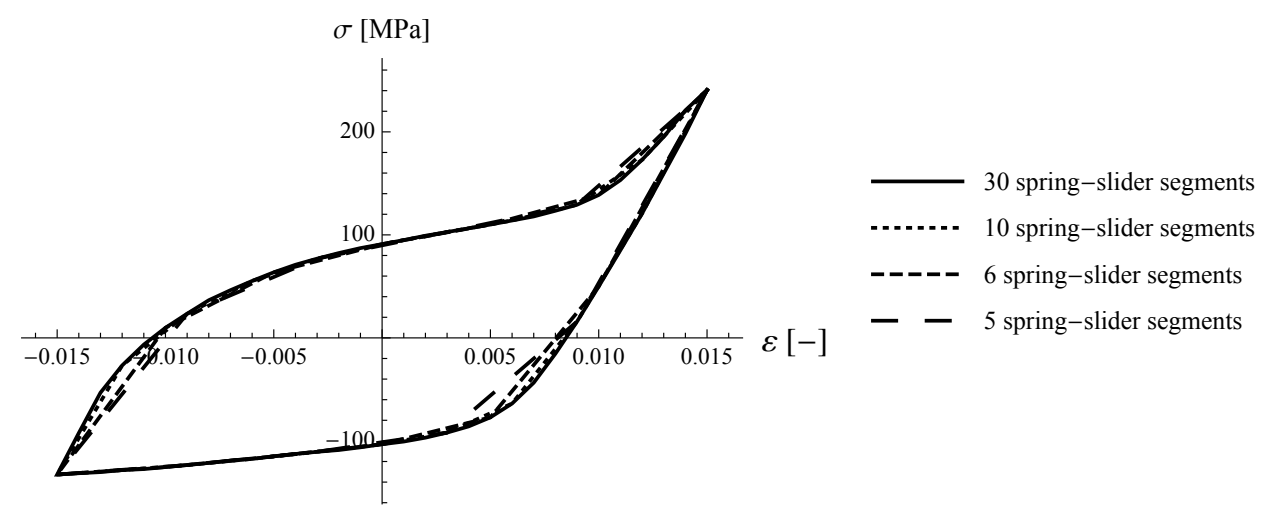

Figure 19: Effect of the number of spring-slider segments per hysteresis branch on the fitting quality of the presented asymmetric Prandtl-Ishlinskii operator.

The effect of the number of reference hysteresis loops used by the Prandtl-Ishlinskii rheological model is presented due to the fact that the measured reference hysteresis loops can exhibit different shapes depending on the loading level. The modelled responses of magnesium AZ31 alloy have been based on seven reference hysteresis loops shown in Figure 4. However, Figure 20 presents the modelled responses for constant $0.6 \%, 0.75 \%, 1.1 \%$ and 
$1.25 \%$ strain amplitude loadings with solid and dashed lines for Prandtl-Ishlinskii rheological models calibrated with seven and four reference hysteresis loops, respectively. In the case of four reference hysteresis loops, cyclic loadings of $0.1 \%, 0.5 \%, 1.0 \%$ and $1.5 \%$ constant strain amplitude were used. Figure 20 shows that Prandtl-Ishlinskii rheological models based on seven and four reference hysteresis loops give comparable simulated responses for magnesium AZ31 alloy. This result validates the robustness of the presented PrandtlIshlinskii rheological model for simulating the response of magnesium AZ31 alloy subjected to cyclic loading at strain amplitudes which were not experimentally determined.

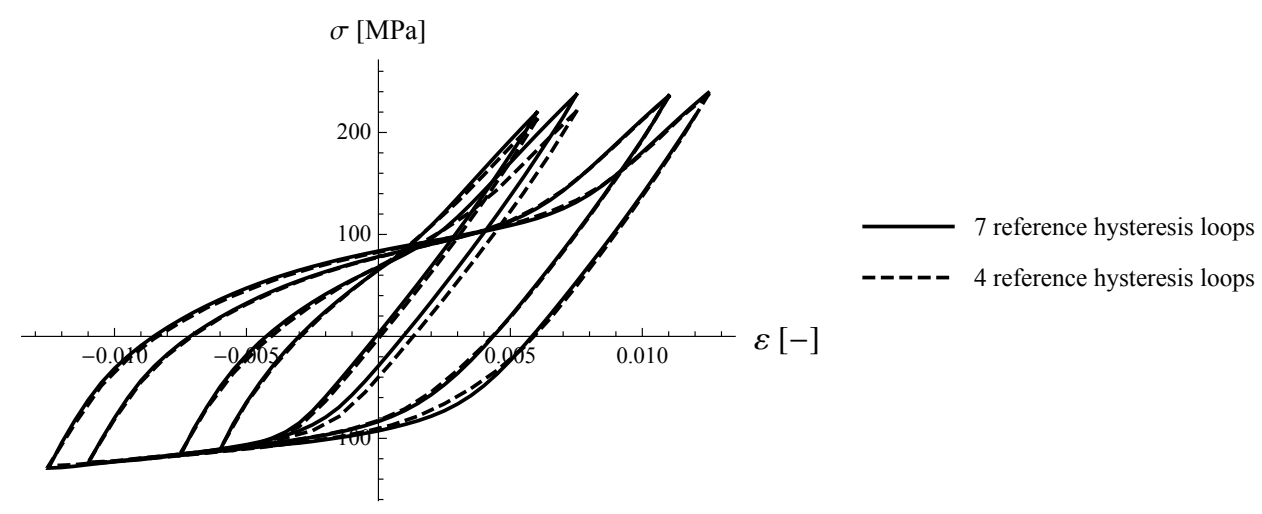

Figure 20: Effect of the number of reference hysteresis loops used in the presented Prandtl-Ishlinskii rheological model on simulated response to constant $0.6 \%, 0.75 \%, 1.1 \%$ and $1.25 \%$ true strain amplitude loading.

The presented modelling technique is verified for cyclic loadings with strain amplitudes less than $1.5 \%$. To simulate the response of magnesium AZ31 alloy subjected to cyclic loadings with higher strain amplitudes, the presented modelling technique uses an extrapolation of the largest reference hysteresis loop, yet further experiments under higher loading levels are suggested to obtain accurate reference hysteresis loops. However, the current experimental setup does not allow for higher loading levels of sheet metal specimens due to the compressive failure by buckling around their strong axes. 


\section{Conclusions}

This paper presents a new technique for modelling the asymmetric material response of magnesium AZ31 alloy sheets subjected to arbitrary uniaxial loading under isothermal conditions. The technique uses a modified Prandtl-Ishlinskii rheological model of parallel connected spring-slider segments to calculate the material stress-strain state. Measurements of the material response to block loadings with variable strain amplitude indicate that major and minor loops are compliant with Madelung's memory rules. The proposed rheological model enables simulation of asymmetric major and minor loops. The shape of asymmetric major loops is determined by maximum absolute strain achieved during the loading history. The shape of a minor loop is predicted depending on the location of its initiation on the major loop. From a comparison of simulated and measured responses of the magnesium alloy to various block loadings it can be concluded that the modelling technique presented here accurately predicts the material stress-strain state under arbitrary uniaxial cyclic loading at room temperature. As the modelling technique is computationally undemanding, it represents a valuable starting point for estimating fatigue life using the energy approach which is predominantly applied for magnesium alloys [25, 33, 55, 58, 59] due to their asymmetric stress-strain response to cyclic loadings.

\section{Acknowledgement}

The authors acknowledge the project EVA4green (operation number: OP20.00362), which was supported financially by the Slovenian Ministry of Education, Science and Sport. The authors also acknowledge financial support from the Slovenian Research Agency (research core funding No. P2-0182 entitled Development evaluation).

\section{Appendix A. Implementation of the proposed Prandtl-Ishlinskii rheological model}

A pseudocode for calculating the material response to uniaxial cyclic loading according to the proposed Prandtl-Ishlinskii method is presented in Algorithm 1. Algorithm 2 and Algorithm 3. Calculation of the current stress $\sigma_{i}\left(t_{k}\right)$ in deformation mechanism $i \in\{U, T\}$ 
is presented in Algorithm 4. Functions OperatorU and OperatorT calculate stress with one side hysteresis operators (4) and (5), respectively. To enhance the computation speed, Prandtl densities $\alpha_{i j}\left(\varepsilon_{m}\right)$ in every spring-slider segment $j \in\left\{1, \ldots, n_{q}\right\}$ for all deformation mechanisms $i \in\{U, T, U 0, T 0\}$ and possible maximum strains $\varepsilon_{m}, m \in\left\{1, \ldots, n_{p}\right\}$, together with the accompanying fictive yield strains $q_{i j}$, are determined before the simulation and stored in a table. The strain loading history $\varepsilon=\left\{\varepsilon\left(t_{1}\right), \ldots, \varepsilon\left(t_{n}\right)\right\}$ is provided for time steps $t_{1} \leq t_{2} \leq \ldots \leq t_{k} \leq \ldots \leq t_{n}$. The output data is a stress series $\boldsymbol{\sigma}=\left\{\sigma\left(t_{1}\right), \ldots, \sigma\left(t_{n}\right)\right\}$ corresponding to strain series $\varepsilon$. The current stress $\sigma\left(t_{k}\right)$ is calculated exclusively from the current data known at time step $t_{k}$.

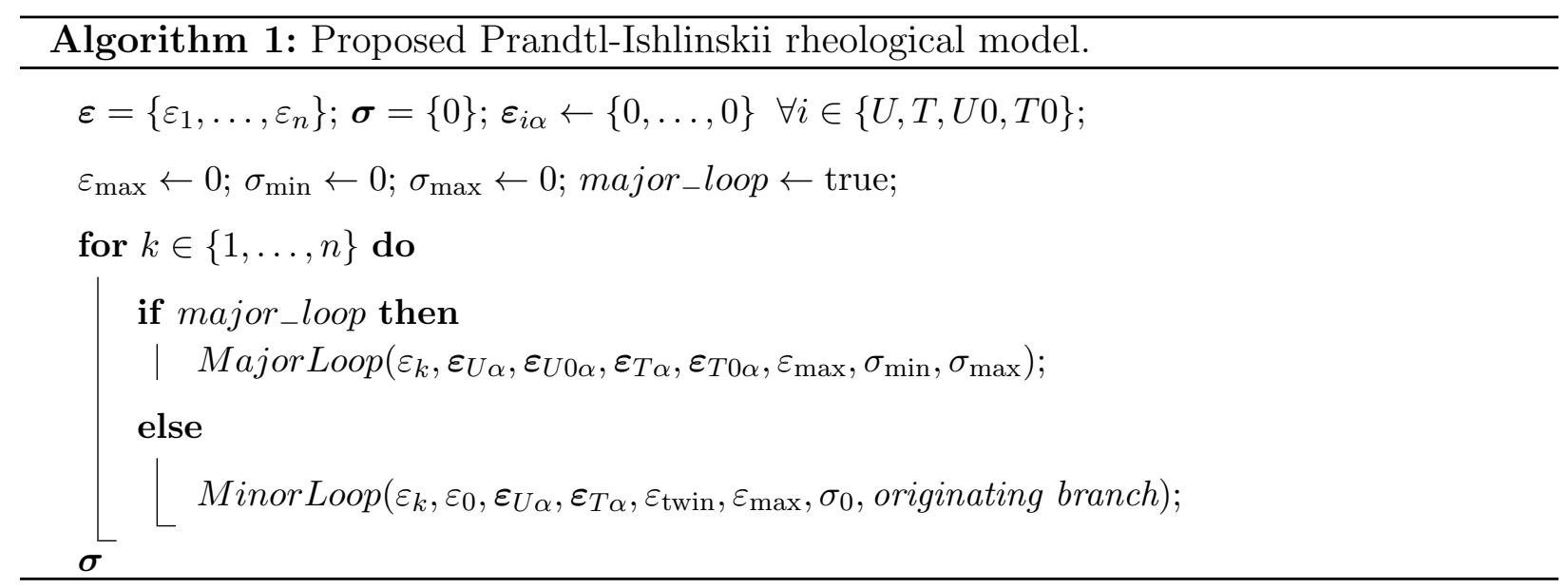

In the first time step Algorithm 1 calls Algorithm 2 to start the simulation either with deformation mechanism $U 0$ for a cyclic tension curve or with deformation mechanism $T 0$ for a cyclic compression curve. Upon reverse in loading direction is maximum absolute strain saved as $\varepsilon_{\max }$, last calculated stress as $\sigma_{\min }$ or $\sigma_{\max }$ depending on loading direction. All active play operators are reset to initial values. In the next time step Algorithm 2 starts a major loop branch at $\left(\varepsilon_{\max }, \sigma_{\max }\right)$ or $\left(-\varepsilon_{\max }, \sigma_{\min }\right)$ depending on the loading direction. The stress-strain state is modelled with deformation mechanism $U$ for the ascending branch or with deformation mechanism $T$ for the descending branch. All active play operators are reset upon each change in the loading direction. The current maximum absolute strain $\varepsilon_{\max }$, maximum stress $\sigma_{\max }$ and minimum stress $\sigma_{\min }$ are updated if exceeded. A transition to 
higher loading level follows the cyclic tension or cyclic compression curve depending on the loading direction.

Algorithm 3 calculates the stress-strain state of minor loops. A minor loop originates on an originating branch of a major loop at a starting point $\left(\varepsilon_{0}, \sigma_{0}\right)$. The shape of the minor loop is determined by an initial strain $\varepsilon_{0}$, a maximum absolute strain $\varepsilon_{\max }$ and strain threshold $\varepsilon_{\text {twin. }}$. Minor loops originating on the ascending branch of a major loop are simulated exclusively as symmetric. However, minor loops originating on the descending branch of a major loop can become asymmetric if its strain range exceeds $\varepsilon_{\max } / 2$ and are reaching in strain area beyond threshold $\varepsilon_{\text {twin }}$. For such a minor loop in the time step when loading direction changes from tensile to compressive, parameters determining the current ascending curve $\left(\varepsilon_{01}, \sigma_{01}\right.$ and $\left.\varepsilon_{\max 1}\right)$ are saved and all active play operators are reset. In the next time step Algorithm 3 is called at the starting point $\left(\varepsilon_{k-1}, \sigma_{k-1}\right)$ and the originating branch is set to ascending. If eventually the stress-strain trajectory of such a minor loop crosses the trajectory of the asymmetric ascending branch for which variables were saved, the stress-strain state of the loop follows the trajectory of the latter in compliance with Madelung's memory rules. Nested minor loops are modelled as symmetric in compliance with Madelung's memory rules. At a time step when a minor loop crosses the major loop, the stress-strain trajectory follows the latter, hence, Algorithm 3 resets all active play operators and returns the calculation to Algorithm 1 . 


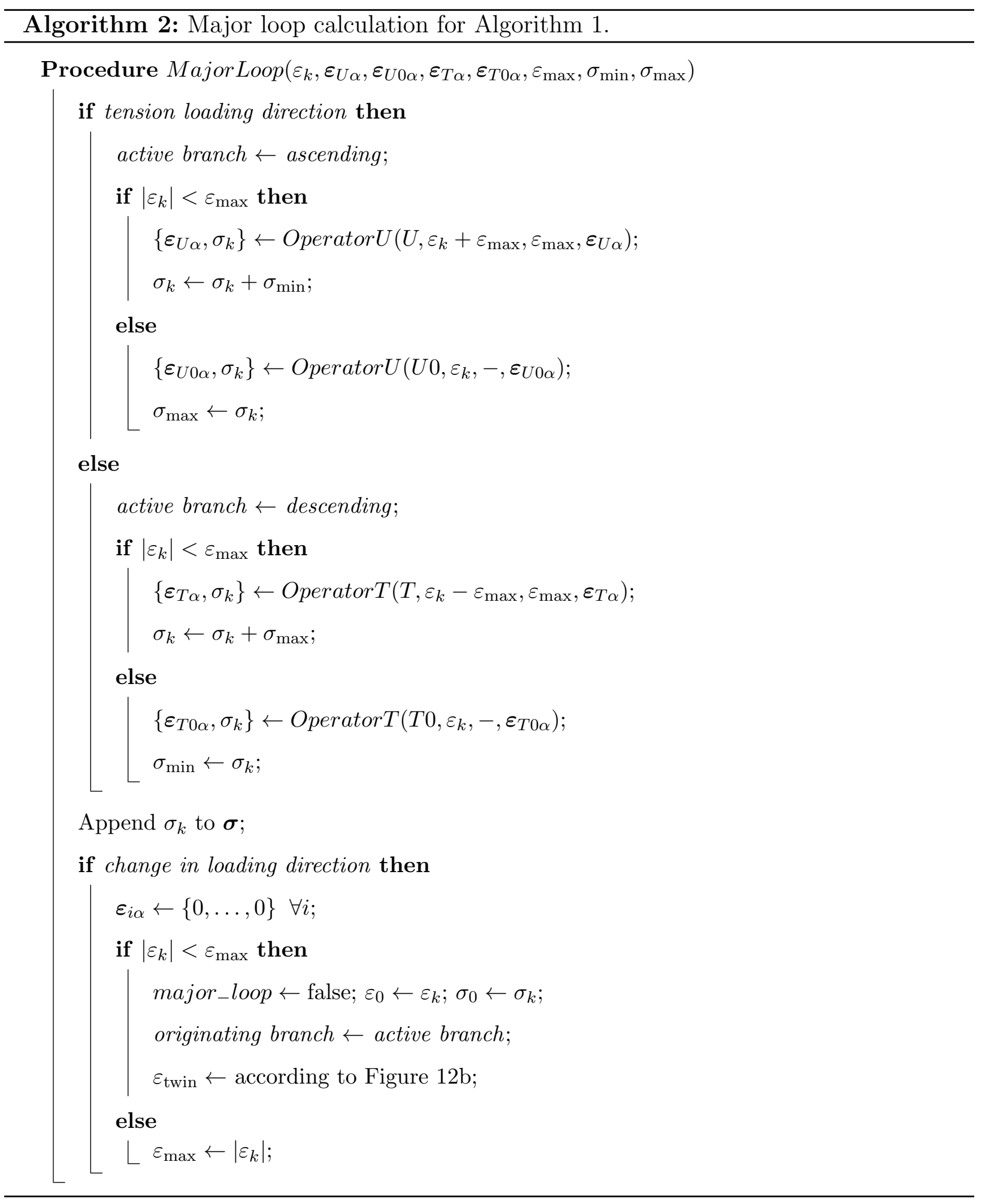




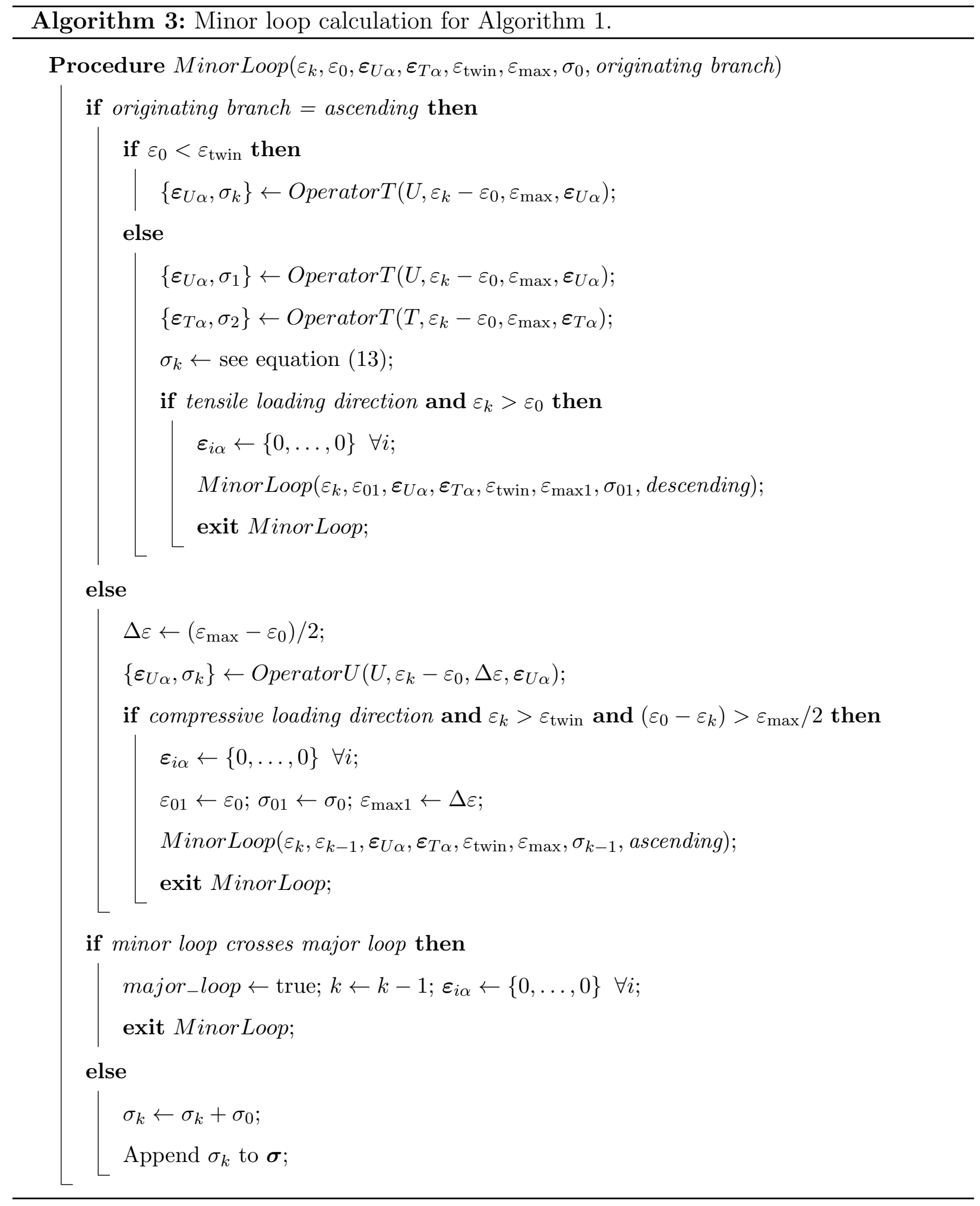




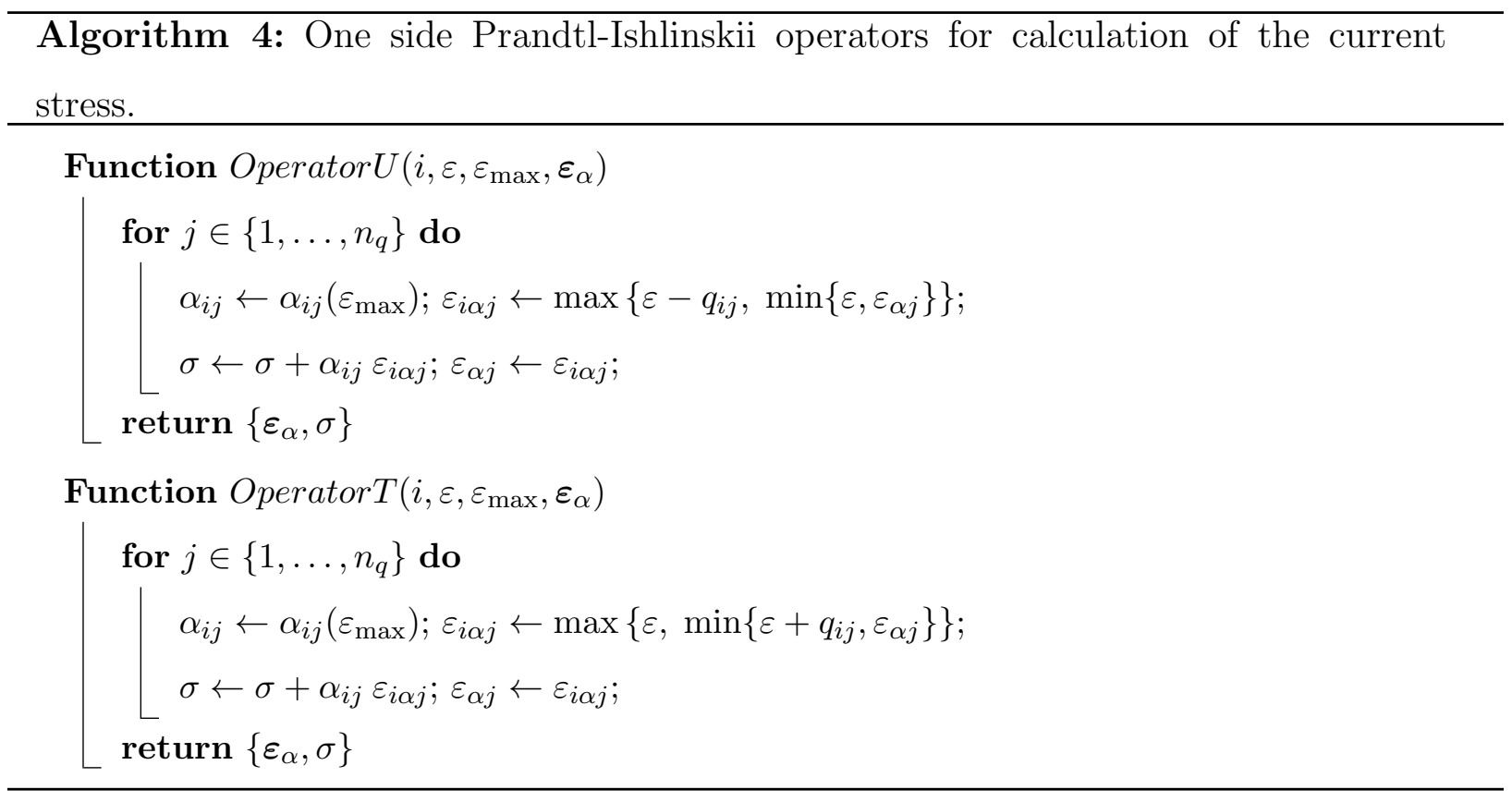

\section{References}

[1] B. L. Mordike, T. Ebert, Magnesium applications potential, Journal of Material Science Engineering A 302 (2001) 37-45.

[2] K. Tadataka, S. Masami, Automotive applications of magnesium alloy, Materials Science Forum 419-422 (2003) 67-72.

[3] S. Gerald, Issues that influence magnesiums use in the automotive industry, Materials Science Forum 419-422 (2003) 43-50.

[4] E. Doege, K. Dröder, Sheet metal forming of magnesium wrought alloys formability and process technology, Journal of Materials Processing Technology 115 (2001) 14-19.

[5] S. Agnew, O. Duygulu, Plastic anisotropy and the role of non-basal slip in magnesium alloy AZ31B, International Journal of Plasticity 21 (2005) 1161-1193.

[6] F. Kabirian, A. S. Khan, T. Gnäupel-Herlod, Visco-plastic modeling of mechanical responses and texture evolution in extruded AZ31 magnesium alloy for various loading condition, International Journal of Plasticity 68 (2015) 1-20.

[7] A. Khan, P. Pandey, T. Gnäupel-Herold, R. Mishrad, Mechanical response and texture evolution of AZ31 alloy at large strains for different strain rates and temperatures, International Journal of Plasticity 27 (2011) 688-706.

[8] D. Ghaffari Tari, M. Worswick, U. Ali, M. Gharghouri, Mechanical response of AZ31B magnesium alloy: Experimental characterization and material modeling considering proportional loading at room 
temperature, International Journal of Plasticity 55 (2014) 247-267.

[9] N. Nguyen, M. Lee, J. Kim, H. Kim, A practical constitutive model for AZ31B Mg alloy sheets with unusual stress-strain response, Finite Elements in Analysis and Design 76 (2013) 39-49.

[10] D. Yin, J. Wang, J. Liu, X. Zhang, On tensioncompression yield asymmetry in an extruded Mg-3Al-1Zn alloy, J. Alloys Compd. 478 (2009) 789-795.

[11] X. Lou, M. Li, R. Boger, S. Agnew, R. Wagoner, Hardening evolution of AZ31B Mg sheet, International Journal of Plasticity 23 (2007) 44-86.

[12] W. Muhammad, M. Mohammadi, J. Kang, R. K. Mishra, K. Inal, An elasto-plastic constitutive model for evolving asymmetric/anisotropic hardening behavior of AZ31B and ZEK100 magnesium alloy sheets considering monotonic and reverse loading paths, International Journal of Plasticity 70 (2015) 30-59.

[13] J. Nobre, U. Noster, M. Kommeier, A. Dias, B. Scholtes, Deformation asymmetry of AZ31 wrought magnesium alloy, Key Eng. Mater. 230-232 (2002) 267-270.

[14] M. Knezevic, A. Levinson, R. Harris, R. Mishra, R. Doherty, S. Kalidindi, Deformation twinning in AZ31: Influence on strain hardening and texture evolution, Acta Materialia 58 (2010) 6230-6242.

[15] S. Kurkuri, M. Worswick, A. Bardelcik, R. Mishra, J. Carter, Constitutive Behavior of Commercial Grade ZEK100 Magnesium Alloy Sheet over a Wide Range of Strain Rates, Metall. Mater. Trans. A 45 (2014) 3321-3337.

[16] D. Ghaffari Tari, M. Worswick, Experiment and crystal plasticity analysis on plastic deformation of AZ31B Mg alloy sheet under intermediate temperatures: How deformation mechanisms evolve, J. Mater. Process. Technol. 221 (2015) 40-55.

[17] G. Zhou, M. Jain, P. Wu, Y. Shao, D. Li, Y. Peng, Experiment and crystal plasticity analysis on plastic deformation of AZ31B Mg alloy sheet under intermediate temperatures: How deformation mechanisms evolve, Int. J. Plast. 79 (2016) 19-47.

[18] M. Li, X. Lou, J. Kim, R. Wagoner, An efficient constitutive model for room-tempearture, low-rate plasticity of annealed Mg AZ31B sheet, Int. J. Plasticity 26 (2010) 820-858.

[19] L. Wu, A. Jain, D. Brown, G. Stoica, S. Agnew, B. Clausen, D. Fielden, P. Liaw, Twinning-detwinning behavior during the strain-controlled low-cycle fatigue testing of a wrought magnesium alloy, ZK60A, Acta Mater. 56 (2008) 688-695.

[20] C. Lee, M. Lee, O. Seo, N. Nguyen, J. Kim, H. Kim, Cyclic behavior of AZ31B Mg: Experiments and non-isothermal forming simulations, Int. J. Plasticity 75 (2015) 39-62.

[21] Y. Wang, J. Huang, The role of twinning and untwinning in yielding behavior in hot-extruded $\mathrm{Mg}-\mathrm{Al}-\mathrm{Zn}$ alloy, Acta Mater. 55 (2007) 897-905.

[22] Y. Xiong, Q. Yu, Y. Jiang, An experimental study of cyclic plastic deformation of extruded ZK60 magnesium alloy under uniaxial loading at room temperature, Int. J. Plasticity 53 (2013) 107-124. 
[23] F. Lv, F. Yang, Q. Duan, Y. Yang, S. Wu, S. Li, Z. Zhang, Fatigue properties of rolled magnesium alloy (AZ31) sheet: Influence of specimen orientation, Int. J. of Fatigue 33 (2011) 672-682.

[24] Y. Xiong, Y. Jiang, Fatigue of ZK60 magnesium alloy under uniaxial loading, Int. J. Fatigue 64 (2014) $74-83$.

[25] J. Dallmeier, J. Denk, O. Huber, H. Saage, K. Eigenfeld, A phenomenological stress-strain model for wrought magnesium alloys under elastoplastic strain-controlled variable amplitude loading, International Journal of Fatigue 80 (2015) 306-323.

[26] X. Lin, D. Chen, Strain controlled cyclic deformation behavior of an extruded magnesium alloy, Mater. Sci. Eng. A 496 (2008) 106-113.

[27] Y. Xiong, Y. Jiang, Cyclic deformation and fatigue of rolled AZ80 magnesium alloy along different material orientations, Mater. Sci. Eng. A 677 (2016) 58-67.

[28] E. Kalatehmollaei, H. Mahmoudi-Asl, H. Jahed, An asymmetric elastic-plastic analysis of the loadcontrolled rotating bending test and its application in the fatigue life estimation of wrought magnesium AZ31B, International Journal of Fatigue 64 (2014) 33-41.

[29] H. Li, G. Kang, Y. Liu, H. Jiang, Non-proportionally multiaxial cyclic deformation of AZ31 magnesium alloy: Experimental observations, Mater. Sci. Eng. A 671 (2016) 70-81.

[30] S. Yin, H. Yang, S. Li, S. Wu, F. Yang, Cyclic deformation behavior of as-extruded Mg $3 \% \mathrm{Al} 1 \% \mathrm{Zn}$, Scripta Materialia 58 (2008) 751-754.

[31] J. Zhang, Q. Yu, Y. Jiang, Q. Li, An experimental study of cyclic deformation of extruded AZ61A magnesium alloy, International Journal of Plasticity 27 (2011) 768-787.

[32] K. Hazeli, H. Askari, J. Cuadra, F. Streller, R. Carpick, H. Zbib, A. Kontsos, Microstructure-sensitive investigation of magnesium alloy fatigue, International Journal of Plasticity 68 (2015) 55-76.

[33] H. Jahed, J. Albinmousa, Multiaxial behaviour of wrought magnesium alloys a review and suitability of energy-based fatigue life model, Theoretical and Applied Fracture Mechanics 73 (2014) 97-108.

[34] G. Masing, Eigenspannungen und verfestigung beim messing, Proceedings of the Second International Congress for Applied Mechanics, Zurich, Switzerland, 1926.

[35] M. Brokate, J. Sperkels, Hysteresis and phase transitions, Springer, New York, 1996.

[36] P. Jayakumar, Modeling and identification in structural dynamics, Report No. EERL 87-01, California Institute of Technology, Pasadena, 1987.

[37] M. Lee, R. Wagoner, J. Lee, K. Chung, H. Kim, Constitutive modeling for anisotropic/asymmetric hardening behavior of magnesium alloy sheets, Int. J. Plasticity 24 (2008) 545-582.

[38] I. A. Zimmermann, Hybrid micro-macro modeling of texture evolution in polycrystal plasticity based on microstructural reorientation continua, Ph.D. thesis, Universität Stuttgart, 2013.

[39] A. Fernández, M. Pérez-Prado, Y. Wei, A. Jérusalem, Continuum modeling of the response of a Mg 
alloy AZ31 rolled sheet during uniaxial deformation, International Journal of Plasticity 27 (2011) $1739-1757$.

[40] G. Proust, C. Tomé, A. Jain, S. Agnew, Modeling the effect of twinning and detwinning during strain-path changes of magnesium alloy AZ31, International Journal of Plasticity 25 (2009) 861-880.

[41] H. Qiao, S. Agnew, P. Wu, Modeling twinning and detwinning behavior of Mg alloy ZK60A during monotonic and cyclic loading, International Journal of Plasticity 65 (2015) 61-84.

[42] W. Wu, H. Qiao, K. An, X. Guo, P. Wu, P. Liaw, Investigation of deformation dynamics in a wrought magnesium alloy, International Journal of Plasticity 62 (2014) 105-120.

[43] J. Kim, D. Kim, Y. Lee, M. Lee, K. Chung, H. Kim, R. Wagoner, A temperature-dependent elastoplastic constitutive model for magnesium alloy AZ31 sheets, Int. J. Plasticity 50 (2013) 66-93.

[44] M. Lee, S. Kim, R. Wagoner, K. Chung, H. Kim, Constitutive modeling for anisotropic/asymmetric hardening behavior of magnesium alloy sheets: application to sheet springback, Int. J. Plasticity 25 (2009) 70-104.

[45] J. Lee, M. Lee, F. Barlat, G. Bae, Piecewise linear approximation of nonlinear unloading-reloading behaviors using a multi-surface approach, Int. J. Plasticity 93 (2017) 112-136.

[46] K. Kuhnen, Modeling, Identification and Compensation of Complex Hysteretic Nonlinearities: A Modified Prandtl-Ishlinskii Approach, European Journal of Control 9 (2003) 407-418.

[47] R. Dong, Y. Tan, A modified Prandtl-Ishlinskii modeling method for hysteresis, Physica Bl 404 (2009) $1336-1342$.

[48] H. Jiang, H. Ji, J. Qiu, Y. Chen, A Modified Prandtl-Ishlinskii Model for Modeling Asymmetric Hysteresis of Piezoelectric Actuators, IEEE Transactions on Ultrasonics, Ferroelectrics, and Frequency Control 57 (2010) 1200-1210.

[49] G. Gu, L. Zhu, C. Su, Modeling and Compensation of Asymmetric Hysteresis Nonlinearity for Piezoceramic Actuators With a Modified Prandtl-Ishlinskii Model, IEEE Transactions on Industrial Electronics 61 (2014) 1583-1595.

[50] M. Nagode, M. Fajdiga, Temperature-stress-strain trajectory modeling during thermo-mechanical fatigue, Fatigue Fract Engng Matr Struct 29 (2005) 175-182.

[51] M. Nagode, M. Fajdiga, Coupled elastoplasticity and viscoplasticity under thermomechanical loading, Fatigue Fract Engng Matr Struct 30 (2007) 510-519.

[52] M. Nagode, F. Längler, M. Hack, A time-dependent damage operator approach to thermo-mechanical fatigue of Ni-resist D-5S, International Journal of Fatigue 33 (2011) 692-699.

[53] K. Piao, J. Lee, J. Kim, H. Kim, R. Wagoner, A sheet tension/compression test for elevated temperatures, Int. J. Plasticity 38 (2012) 27-46.

[54] M. Nagode, M. Fajdiga, Thermo-Mechanical Modelling of Stochastic Stress-Strain States, Journal of 
Mechanical Engineering 52 (2006) 74-84.

[55] S. Park, S. Hong, B. Lee, W. Bang, C. Lee, Low-cycle fatigue characteristics of rolled Mg-3Al-1Zn alloy, Int J Fatigue 32 (2010) 1835-1842.

[56] J. Klemenc, D. Šeruga, M. Nagode, Plastic and total energy as the basis of durability prediction for magnesium alloy AZ31, in: Processing and fabrication of advanced materials-XXVII : proceedings of a conference, 2019.

[57] L. Wu, S. Agnew, Y. Ren, D. Brown, B. Clausen, G. Stoica, H. Wenk, P. Liaw, The effects of texture and extension twinning on the low-cycle fatigue behavior of a rolled magnesium alloy, AZ31B, Materials Science and Engineering: A 527 (2010) 7057-7067.

[58] C. Wang, T. Luo, J. X. Zhou, Y. Yang, Anisotropic cyclic deformation behavior of extruded ZA81M magnesium alloy, Int. J. Fatigue 96 (2017) 178-184.

[59] J. Dallmeier, O. Huber, H. Saage, K. Eigenfeld, Uniaxial cyclic deformation and fatigue behavior of AM50 magnesium alloy sheet metals under symmetric and asymmetric loadings, Materials \& Design 70 (2015) 10-30. 